\title{
Injectable contraceptives: Perspectives and experiences of women and health care providers in India
}

Shireen J. Jejeebhoy

Population Council

A.J. Francis Zavier

Population Council

Follow this and additional works at: https://knowledgecommons.popcouncil.org/departments_sbsr-pgy

Part of the Demography, Population, and Ecology Commons, Family, Life Course, and Society Commons, Gender and Sexuality Commons, International Public Health Commons, Medicine and Health Commons, and the Women's Health Commons

How does access to this work benefit you? Let us know!

\section{Recommended Citation}

Jejeebhoy, Shireen J. and A.J. Francis Zavier. 2012. "Injectable contraceptives: Perspectives and experiences of women and health care providers in India." New Delhi: Population Council. 


\section{Injectable contraceptives: Perspectives and experiences of women and health care providers in India}

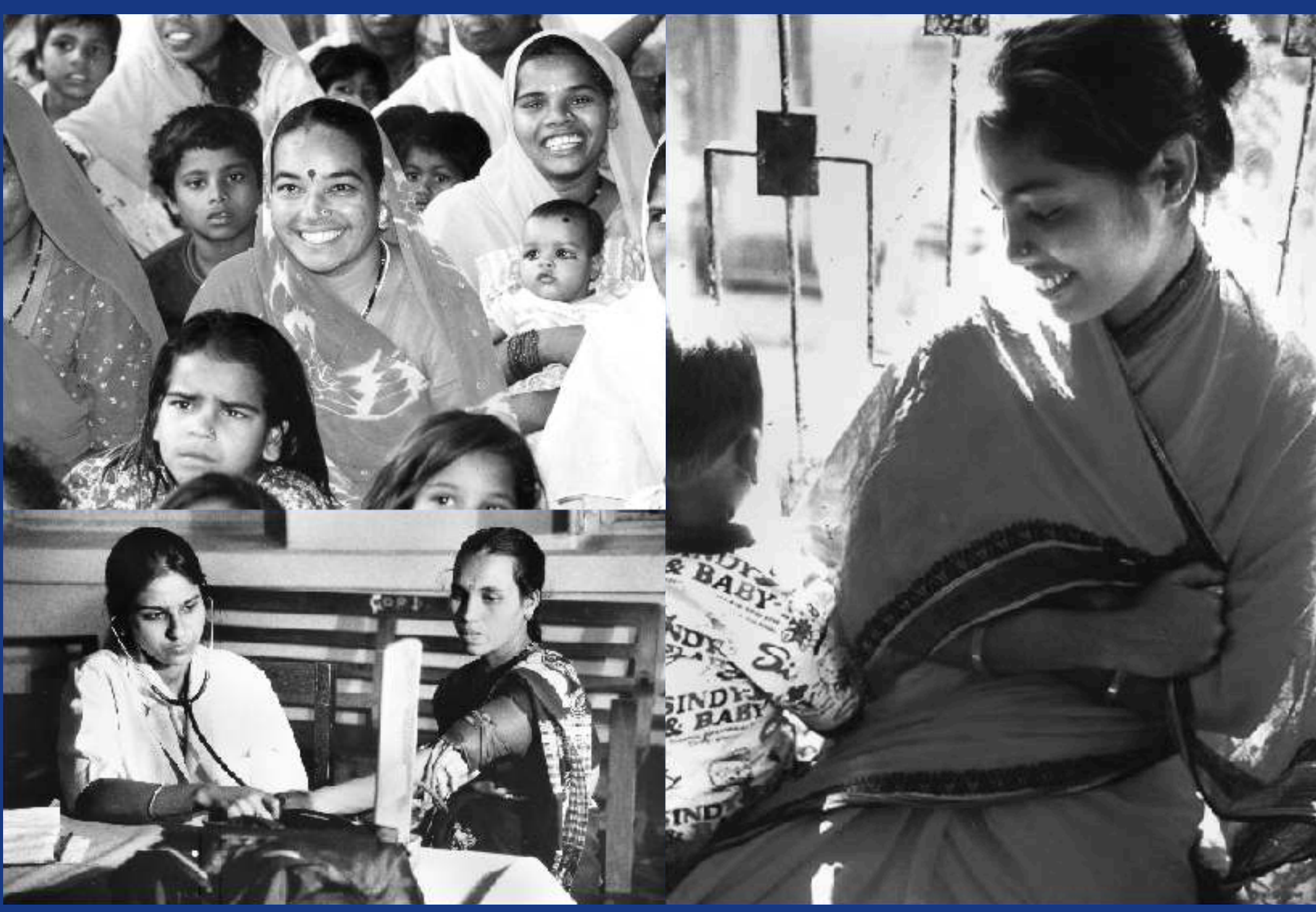


This report is the result of a study, conducted in 2011, that aimed to shed light on the feasibility and acceptability of making injectable contraceptives more widely available to women in India. It synthesises the perspectives and experiences obtained from three study components: a retrospective survey of injectable contraceptive users, a survey comprising exit interviews with new contraceptive method adopters and in-depth interviews with health care providers. The study was located in the facilities and among the clients and health care providers of a range of reproductive health NGOs, including the Family Planning Association of India, Janani, Parivar Seva Sanstha and Population Health Services (India). The facilities were drawn from both urban and peri-urban areas of several states, namely, Bihar, Delhi, Jharkhand, Madhya Pradesh and Maharashtra, and were selected purposively on the basis of the volume of injectable contraceptive users served by each clinic in the two years preceding the study.

For additional copies of this report, please contact:

Population Council

Zone 5-A, Ground Floor

India Habitat Centre

Lodi Road

New Delhi -110003

Phone: 011-2464 2901/02

Email: info-india@popcouncil.org

Website: http://www.popcouncil.org/asia/india.html

The Population Council confronts critical health and development issues from stopping the spread of HIV to improving reproductive health and ensuring that young people lead full and productive lives. Through biomedical, social science, and public health research in 50 countries, we work with our partners to deliver solutions that lead to more effective policies, programmes, and technologies that improve lives around the world. Established in 1952 and headquartered in New York, the Council is a nongovernmental, nonprofit organisation governed by an international board of trustees.

Copyright (C) 2012 Population Council

Suggested citation: Jejeebhoy, S. J. and A. J. Francis Zavier. 2012. Injectable contraceptives: Perspectives and experiences of women and health care providers in India. New Delhi: Population Council. 


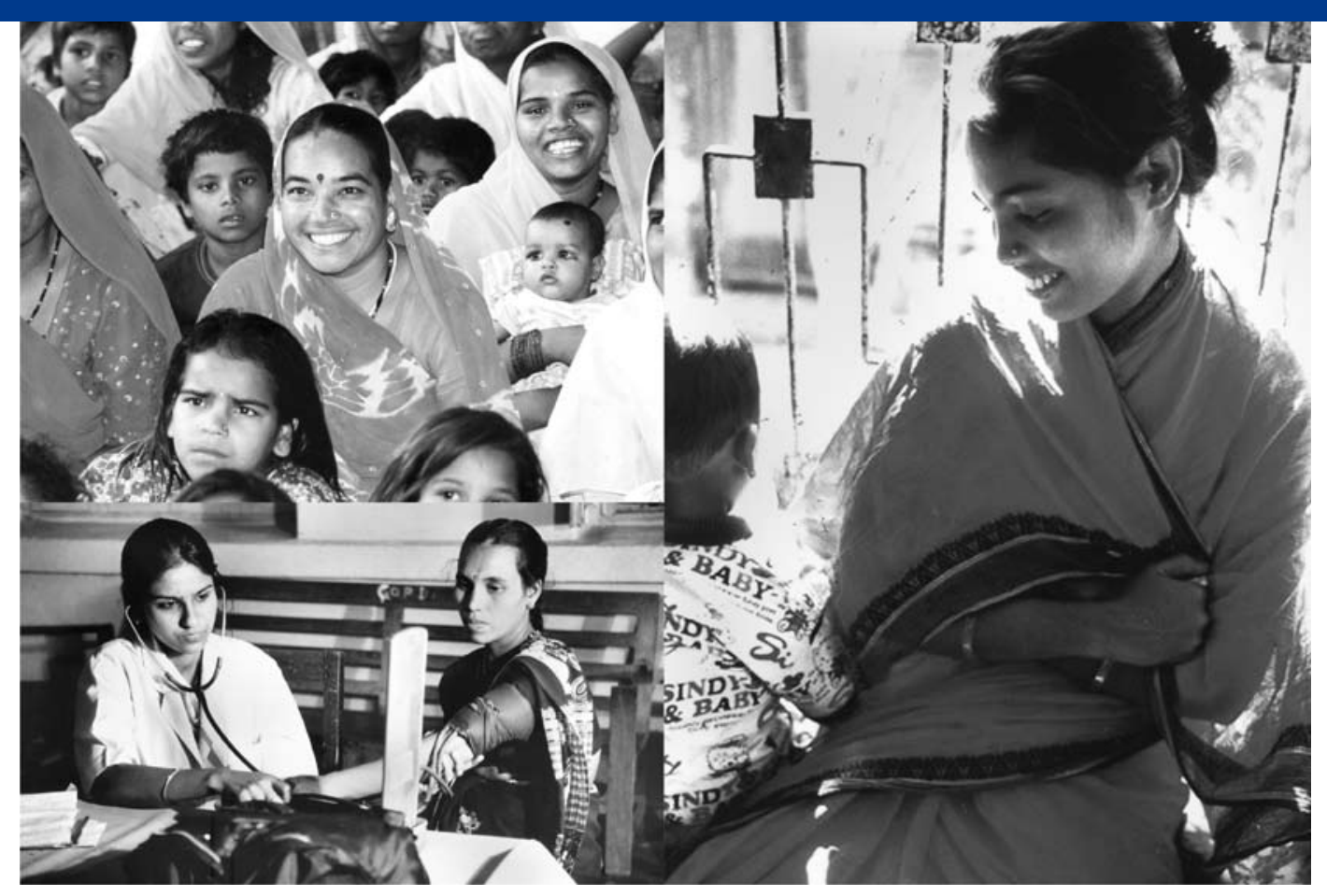

\section{Injectable contraceptives: Perspectives and experiences of women and health care providers in India}

Shireen J. Jejeebhoy

A. J. Francis Zavier 



\section{Contents}

Executive summary $\quad$ ix

Summary $\quad x$

Recommendations $\quad$ xiv

Conclusion $\quad$ xvi

Chapter 1: Introduction 1

Rationale 1

Study Objectives 1

Background $\quad 2$

Study Setting $\quad 4$

$\begin{array}{ll}\text { Study Design } & 6\end{array}$

Study samples and coverage $\quad 6$

Data collection $\quad 8$

Analysis 99

Ethical issues and consent procedures 9

$\begin{array}{ll}\text { Structure of this report } & 10\end{array}$

Chapter 2: Social and demographic characteristics of respondents 11

Chapter 3: Experiences of women using injectable contraceptives $\quad 14$

Decision-making process $\quad 14$

$\begin{array}{ll}\text { Injectable contraceptive counselling } & 17\end{array}$

Side effects experienced $\quad 18$

Method continuation $\quad 21$

Use failure $\quad 22$

Reasons for discontinuation $\quad 22$

Method switching $\quad 25$

Acceptability of injectable contraceptives 26

Factors influencing injectable contraceptive continuation 28

Summary 30 
Chapter 4: Perspectives on injectable contraceptives among women seeking to adopt contraception

Pre-adoption counselling

Method adopted

Method preferences

Summary

Chapter 5: Perspectives of health care providers on injectable contraceptives

Health care provider perceptions about method preferences of clients

Health care provider perceptions about the advantages and disadvantages of injectable contraceptives

Health care provider perceptions about factors dissuading women from adopting injectable contraceptives

Health care provider perceptions on the appropriateness of injectable contraceptives for different groups of women

Injectable contraceptive related counselling offered by health care providers

Health care provider perceptions about follow-up, discontinuation and switching

Health care provider perceptions about the inclusion of injectable contraceptives in the national programme

Summary 


\section{List of tables}

Table $1.1 \quad$ Selected socio-demographic characteristics of study states

Table $1.2 \quad$ Coverage of the study 7

Table 2.1 Socio-demographic profile of respondents 12

Table 3.1 Source of information among women who had adopted injectable contraceptives: Percentage of women who had heard about injectable contraceptives prior to or in the course of seeking contraceptive services by source of information

Table 3.2 Intended contraceptive method: Percentage of women by contraceptive method they had intended to adopt prior to visiting the facility

Table 3.3 Contraceptive decision-making role: Percentage of women by lead decision-maker(s) in the final selection of injectable contraceptives 16

Table 3.4 Injectable contraceptive counselling and information obtained from health care providers 17

Table 3.5 Information provided by health care providers about side effects: Percentage of women who were informed about possible side effects of injectable contraceptives by type of side effect discussed

Table 3.6 Side effects experienced: Percentage of women by types of side effects experienced after each dose of the injectable contraceptive

Table 3.7 Of women experiencing at least one side effect, percentages reporting that they had complained to a health care provider about the side effect and that the side effect had affected their ability to perform household work

Table 3.8 Factors underlying discontinuation: Percentage of women who discontinued use of injectable contraceptives by dose after which the method was discontinued and reason(s) for discontinuation

Table 3.9 Of women who discontinued use of injectable contraceptives, percentages who had switched methods immediately and after a break of one or more months, by method adopted

Table $3.10 \quad$ Perceived features of injectable contraceptives among all women by duration of injectable contraceptive use

Table 3.11 Factors influencing method continuation: Logistic regression, odds ratios ( $95 \%$ confidence intervals)

Table 4.1 Percentage of women seeking to adopt contraception by pre-adoption counselling received

Table 4.2 Percentage of women seeking to adopt contraception by contraceptive method they intended to adopt and the method adopted

Table 4.3 Reasons for non-adoption of injectable contraceptives 


\section{List of figures}

Figure 3.1 Life table continuation rates of injectable contraceptives at the completion of each tri-monthly dose

Figure 3.2 Life table continuation rates of injectable contraceptives at the completion of each tri-monthly dose by side effects experienced

Figure 3.3 Life table all-method contraceptive continuation rates among women who had adopted injectable contraceptives 


\section{Acknowledgements}

This study has benefited immeasurably from the inputs of many. We are extremely grateful to the International Planned Parenthood Federation (IPPF), the Family Planning Association of India (FPAI), and the David and Lucile Packard Foundation for their generous support, which made this study possible. We are also grateful to Kalpana Apte and Manisha Bhise of the Family Planning Association of India, and V. S. Chandrashekhar and Lester Coutinho of the David and Lucile Packard Foundation for their support and suggestions over the course of this project.

This study could not have been undertaken without the generous cooperation of the NGOs who permitted us to locate our study within their facilities, and obtained consent from their clients, former clients and health care providers to be approached and interviewed by our study teams. We are grateful to the Family Planning Association of India in Madhya Pradesh and Maharashtra, Janani in Bihar and Jharkhand, Parivar Seva Sanstha (PSS) in Delhi, and Population Health Services (India) in Jharkhand, for their huge support.

The study benefited from the insights and advice of many during its development, implementation and report preparation stages. Rajib Acharya and Shveta Kalyanwala provided invaluable advice in developing the project design and study instruments. Shilpi Rampal helped in the preparation of the data entry program, and she and Binit Jha were responsible for data management. Anupam Shukla provided helpful comments on the report. Komal Saxena provided valuable support in analysing qualitative data. M.A. Jose ably managed the administrative aspects of this project. Jyoti Moodbidri and Komal Saxena offered valuable editorial inputs that have made the report more readable and accurate, and Komal Saxena coordinated the printing of the report. We are grateful to each of these individuals for their extremely valuable contribution.

An earlier draft of this report was extensively and insightfully peer reviewed by Rajib Acharya, Manisha Bhise and Iqbal Shah. Their thoughtful and provocative comments are much appreciated and have been incorporated into and, thereby, strengthened this report.

Our colleague, the late Rajesh Kumar, was instrumental in initiating the project, including in translating study instruments, training the field team and monitoring fieldwork at the early stages of the project. His untimely death in the course of the project has been an enormous loss to us at the Council. We would like to acknowledge with gratitude his immense contribution to this study.

Our field team members did a commendable job of following up injectable contraceptive users at their homes and collecting data from consenting women efficiently and sensitively. We are grateful to them for their hard work, and for the robust quality of the survey and qualitative data they have collected.

Finally, we would like to acknowledge our study participants for their willingness to participate in this project and share their experiences with us. Our survey respondents shared with us their experiences and perspectives with regard to injectable contraceptives, their motivations for adopting or not adopting the 
method, and their experiences, both positive and negative, while using the method. The health care providers generously gave us their time, and provided us with valuable information relating to their experiences and perspectives on the wider use of injectable contraceptives. We are grateful to all of our study participants for sharing these details with us.

Shireen J. Jejeebhoy

A. J. Francis Zavier 


\section{Executive summary}

Injectable contraceptives are associated globally with low failure rates but lower continuation rates than such other methods as the oral contraceptive pill and intrauterine contraceptive device (IUCD). Injectable contraceptives, notably depot medroxyprogesterone acetate (DMPA) and norethisterone enanthate (NET-EN), have been approved for commercial sale in India by the Drugs Controller General of India, and it is DMPA that is the method used in India. However, injectable contraceptives have not been provided in the basket of contraceptive methods available under the Reproductive and Child Health programme in India, largely because of fears expressed about their appropriateness for women in India and the quality of services. As such, injectable contraceptives are available only through private or social marketing channels, because of which their use is limited.

Against this background, the Population Council undertook research to shed light on the feasibility and acceptability of making injectable contraceptives more widely available to women in India. The study focused on injectable contraceptive users, new method adopters and health care providers drawn from the facilities of a range of reproductive health NGOs, including the Family Planning Association of India, Janani, Parivar Seva Sanstha and Population Health Services (India). The facilities were drawn from both urban and peri-urban areas of several states, namely, Bihar, Delhi, Jharkhand, Madhya Pradesh and Maharashtra, and were selected purposively on the basis of the volume of injectable contraceptive users served by each clinic in the two years preceding the study. A total of 27 facilities were selected for the study.

The study assessed these issues from three perspectives. A retrospective survey was conducted that followed up a total of 375 women who had adopted injectable contraceptives at any time at least 12 months prior to the interview in the participating facility, in order to assess the experiences of injectable contraceptive users, including the decision-making process; use histories; discontinuation and switching, and factors underlying discontinuation; side effects experienced and the acceptability of these side effects; the quality of care received, including whether the counselling and information provided were comprehensive and follow-up appropriate, and the overall acceptability of the method. Second, a survey of 117 women seeking contraception was fielded that assessed, through exit interviews, women's awareness of injectable contraceptives; contraceptive information provided by the health care provider, including whether injectable contraceptives had been offered; the method selected and reasons underlying acceptance or non-acceptance of injectable contraceptives. Third, in-depth interviews were held with 16 health care providers to draw out health care provider perspectives about the advantages and disadvantages of injectable contraceptives, the experiences of women using injectable contraceptives, the kinds of counselling and follow-up provided to women who adopted injectable contraceptives, and the extent to which health care providers would advocate the inclusion of injectable contraceptives in the public health programme. 


\section{Summary}

\section{There is a demand for injectable contraceptives}

Exit interviews with women seeking to adopt contraception revealed that nine percent of women seeking contraception at study facilities, that is, about one-fifth of those opting for a non-terminal method, had adopted injectable contraceptives. We acknowledge that the NGO facilities in which the study was located were well known for offering injectable contraceptives; and hence their clientele may not be representative of all women seeking to adopt contraception more generally. Nevertheless, findings demonstrate that there is clearly a demand for injectable contraceptives in diverse settings in India.

\section{A number of factors inhibited women seeking contraception at study facilities from adopting injectable contraceptives}

Findings suggest a number of factors underlying the relatively limited adoption of this method. Among women seeking contraceptive services, many of those who had not intended to adopt injectable contraceptives were unaware of the method. Indeed, two-thirds of those who had adopted other methods reported that they were unaware of the availability of injectable contraceptives. As most women adopted the method they had intended to adopt prior to visiting the facility on the day of the interview, this lack of general awareness is likely a key factor inhibiting the use of injectable contraceptives. Women who had adopted injectable contraceptives advanced other reasons such as fear of side effects, and the cost of injectable contraceptive repeat doses. In addition, the need to access the facility for repeat doses of injectable contraceptives was perceived as a serious disadvantage by many; in comparison, they noted that the IUCD did not require repeated follow-up and oral contraceptives could be easily purchased or obtained from facilities and outlets closer to home.

\section{Experience of side effects was widespread among injectable contraceptive users}

As other studies have observed, more than four in five women who adopted injectable contraceptives had experienced at least one side effect, largely menstrual disturbances or backache, weakness and weight gain. However, of women who had continued using injectable contraceptives for three or more doses, a comparison of side effects experienced following the first and third or higher order dose, suggested that side effects, notably heavy bleeding and irregular menstrual cycles were considerably less likely to be experienced following subsequent doses compared to following the first dose. In all, about three-fifths of all women who experienced a side effect had complained about it to a health care provider and about half noted that the side effect affected their ability to perform their household responsibilities, both in terms of physical inability to perform routine tasks and in terms of the cultural proscriptions forbidding women to enter the kitchen, perform pujas or visit a place of worship during menstruation. Indeed, women who had experienced three or more side effects were more likely than other women to so report; women who experienced menstrual disturbances were, on average, less likely to have complained and less likely to have reported that the side effect had affected their ability to perform their household responsibilities than were those who had experienced other side effects. 


\section{Method continuation was limited}

Conforming with the thrust of available evidence, both global and from India, our findings suggest that method continuation was limited. Life table continuation rates suggest that many women discontinued using the method after the first injection, and by 12 months, just 23 percent were continuing to use injectable contraceptives. Reasons for discontinuation centred largely around the side effects experienced, with twothirds of all those who had discontinued using injectable contraceptives, citing a health-related factor, largely menstrual disturbances, as the reason. Many fewer cited method-related reasons (that they planned to switch to another method, did not like the method, had doubts about it, needed a break from it or that it was inconvenient to use), difficulties in accessing supplies, and fertility-related reasons (that they wanted to become pregnant, were infecund or did not engage in sexual relations regularly); one woman reported use failure. That side effects were a central reason for discontinuing injectable contraceptive use was evident from findings suggesting that life table continuation rates were considerably lower among those who experienced both menstrual disturbances and other side effects than among those who experienced just menstrual disturbances.

Continuation of use of injectable contraceptives, as assessed by multivariate analysis, was largely associated with a number of socio-demographic and use-related factors. The odds that a woman had continued to use injectable contraceptives for at least 12 months were greater among younger and better-educated women, and those with larger numbers of children at the time of taking the first dose of injectable contraceptives, as compared to other women, Notably, they were also greater among those who experienced fewer side effects and were provided good quality of care. Also of interest were findings that continuation of injectable contraceptives at early stages of use were significantly associated with whether the decision to adopt injectable contraceptives was made jointly by the woman and her husband, suggesting that the husband's role in supporting women was important for method continuation at the initial stages of use.

In in-depth interviews, health care providers concurred that the leading reason for discontinuing injectable contraceptive use was the experience of side effects, notably menstrual disturbances. Other reasons mentioned included the inconvenience of returning to the facility every three months for re-injections and cost. Health care providers highlighted that a range of reasons inhibited women experiencing menstrual disturbances from continuing to use injectable contraceptives; for example, those experiencing heavy bleeding or irregular periods feared that they had a serious disease, those experiencing amenorrhoea feared that they were pregnant, and discontinued the method as a result; and cultural practices that forbid menstruating women from entering the kitchen or performing religious activities, including visiting a place of worship, prompted women who experienced heavy bleeding or irregular menstruation to discontinue using injectable contraceptives because it affected their ability to perform these regular tasks. Several health care providers also noted that weight gain and the long waiting time to conception following discontinuation of the method were additional reasons for discontinuation. 


\section{Following discontinuation, large proportions of women switched to using a different contraceptive method}

Following discontinuation of injectable contraceptive use, about three in ten women switched immediately to another contraceptive method, a similar proportion switched to another method (including those who switched back to injectable contraceptives) after a gap of one to three months, and about two in five women did not adopt another method even after a three months gap. Using these two indicators of all-method continuation, findings showed 12-month continuation rates of 45 percent and 53 percent, respectively.

In in-depth interviews, health care providers also noted that method switching was common among women who discontinued using injectable contraceptives for method-related reasons, and that the two methods to which women most commonly switched were tubal ligation and the IUCD.

\section{Counselling was not comprehensive for most women who adopted injectable contraceptives}

Findings from women who had adopted injectable contraceptives suggest that although the majority had obtained information about injectable contraception largely from health care providers, counselling was not comprehensive in many instances. For example, while almost all women who had adopted injectable contraceptives had been informed about the need for three-monthly re-injections and their cost, and most had been informed about how the method works and the fact that it is a non-terminal method, fewer than three in five had been counselled about possible side effects, what to do if problems were encountered, and the need to return to the health care provider or facility if doubts or problems were experienced.

Exit interviews with women seeking contraception at study facilities suggest that they had similar experiences. Few women reported that counselling had encompassed information about injectable contraceptives and their advantages and disadvantages. Indeed, just one in four women seeking contraception reported that they had been informed about the availability of injectable contraceptives during pre-adoption counselling by the health care provider.

Health care provider perceptions, as espoused in in-depth interviews, differed. Health care provider narratives suggest that counselling encompassed both the provision of information and an assessment of the prospective client's suitability for injectable contraceptives. Counselling was held to entail the provision of such information as the mechanics of the method (how often it must be taken) and the kind of side effects that may occur. All health care providers indicated that they informed women about such side effects as amenorrhoea and heavy bleeding, and that they should return to the clinic if they experienced these. Other side effects were mentioned less frequently (weight gain for example). Several health care providers discussed the importance of including the husband in the counselling session, highlighting the link between the husband's involvement and the quality of subsequent method use, and the perception that many women would not adopt a method without having discussed it with their husband. All health care providers emphasised that the final decision on method use was made by the woman herself, alone or together with her husband. Finally, while a number of health care providers noted that poor and poorly educated women found 
it more difficult than others to comprehend the information provided, and that they may not continue using the method because of the high cost of re-injections, the large majority stressed that they would not deny injectable contraceptives to poor and poorly educated women.

\section{Women and providers were divided about the acceptability of injectable contraceptives}

Overall, women were divided about the acceptability of injectable contraceptives. As many as one quarter of all women could not identify a single positive feature, and a slightly larger proportion could not identify a single negative feature of injectable contraceptives. Key positive features included that it enabled women to control their fertility, that it was long-acting and does not require a daily routine, that it is easy to use and that it is safe. Key negative features, as expected, were the menstrual disturbances and other health-related side effects caused by injectable contraceptives. Women who had discontinued the method before completing 12 months of use (three doses or fewer) were more likely than those who had continued using the method for 12 months or more (at least four doses) to report negative features and correspondingly, were significantly more likely to report such positive features as its safety and effectiveness, and its long-acting nature and ease of use than were those who had discontinued before completing 12 months of use. Over half of women who had used injectable contraceptives as well as the IUCD or oral contraceptive pills (prior to adoption of injectable contraceptives or post discontinuation) reported that they preferred to use injectable contraceptives. Leading reasons for this preference included its perceived safety, ease of use, long-acting nature and, in comparison to oral contraceptive pills, that it does not require a daily routine.

In in-depth interviews, health care providers corroborated many of the issues raised by women who had used injectable contraceptives and those seeking to adopt a contraceptive method. Most health care providers noted that a number of their clients had adopted injectable contraceptives and that interest in the method was frequently expressed. However, they were mixed about their views on the appropriateness of injectable contraceptives as a viable method for their clientele. Almost all agreed that it is a safe and effective method, but expressed concerns about the side effects of the method. Several health care providers indicated that they would recommend the method to only certain categories of women, for example, those who do not want another child, or are older. Many noted that menstrual disturbances made injectable contraceptives an unattractive option for women, arguing that neither heavy bleeding nor amenorrhoea were acceptable side effects for women. A number of health care providers also noted that for women intending to have another pregnancy on discontinuation of the method; time to conception was far longer than that associated with the IUCD or oral contraceptives. Notably, not a single health care provider acknowledged the appropriateness of injectable contraceptives for recently delivered and lactating women.

Notwithstanding these concerns, health care providers were, for the most part, in favour of including injectable contraceptives in the national programme in order that the basket of methods available to women would increase and provide women with greater choice. However, they argued strongly for certain prerequisites, such as comprehensive and sensitive counselling and effective follow-up, for example. A few were sceptical; they believed that even with such improvements in the quality of services, few women in India would adopt or continue using injectable contraceptives because their side effects, and notably menstrual disturbances, would discourage most women for both health and socio-cultural reasons. 


\section{Recommendations}

The findings of the study suggest a number of priority areas for action.

Meet the demand for injectable contraceptives by including the method in the basket of contraceptives provided in public sector facilities

Findings highlight that there is considerable interest in adopting injectable contraceptives and clearly a demand for a safe and effective non-terminal method that allows women to control their fertility confidentially, that does not require daily attention and that does not require to be inserted. Relatively low continuation rates are associated with injectable contraceptives globally and the finding should not be interpreted as a lack of demand. Indeed, the finding that more than one-fifth of all injectable contraceptive users continued the method for 12 months reiterates that there exists a demand for the method among certain groups of women. At the same time, evidence that many more discontinue injectable contraceptive use and immediately switch to a different method, thereby remaining protected against unintended pregnancy, suggests that injectable contraceptives play an important role in women's overall contraceptive strategies. Expanding the basket of contraceptives available to women will, therefore, enhance women's options and enable them to select the one whose features most suit their needs.

\section{Include a component of injectable contraceptives in the training offered to a range of health care providers}

Findings have suggested that health care providers who serve injectable contraceptive users may not be fully aware of the advantages and disadvantages of injectable contraceptives, the full range of side effects that are and are not associated with injectable contraceptives, and the counselling needs of potential users. It is important, therefore, to include a module on injectable contraceptives in the contraception-related training offered to a range of health care providers. For example, health care providers must be made aware of the appropriateness of injectable contraceptives for women who are recently delivered and lactating. Similarly, they should be trained to recognise that injectable contraceptives may satisfy the needs of women at different stages of the life cycle, for example, a newly delivered woman who wishes to space her next pregnancy, or a woman who is not medically eligible for an IUCD or does not want to have an IUCD inserted but is looking for a long-acting method. At the same time, they should be trained to appreciate that for some women, common side effects would likely be an intolerable disturbance in everyday life, and hence, should be equipped to counsel women so as to enable the woman to arrive at an informed decision about whether or not to adopt injectable contraceptives.

Given that a number of women from our study were drawn from rural areas, it is important that training for frontline health workers, such as ANMs, ASHAs and AWWs, should also include information about injectable contraceptives, how they function and where they can be obtained, as well as basic information about potential side effects and how these should be managed. 


\section{Expand awareness of injectable contraceptives at the community level}

Findings have confirmed that many women seeking to adopt contraceptives were unaware of injectable contraceptives, and at the same time, although the method is not available through the programme, a sizeable number of women do indeed opt for it. It is important, therefore, that efforts are made to inform communities, and women in particular, about injectable contraceptives, how they function, their cost, and where they can be obtained, as well as basic information about potential side effects.

\section{Improve the quality of care and counselling provided to injectable contraceptive users}

Findings suggest a disconnect between the views of health care providers on the comprehensiveness of counselling provided and women's views about the comprehensiveness of counselling received from health care providers with regard to injectable contraceptives. This disconnect highlights the need for health care providers to ensure that women are indeed making an informed choice, that they fully understand the implications of likely side effects for their life. Health care providers have acknowledged the importance of including husbands in the counselling session, and findings have confirmed that continuation beyond the first dose is indeed influenced by the role of the husband in decision-making. Provided that the woman agrees, it is important that counselling includes both the woman and her husband and that both are made fully cognisant of possible side effects.

As far as counselling is concerned, health care providers must be trained to ensure that counselling encompasses the full range of side effects associated with injectable contraceptives, as well as the action that the woman should take in case these side effects are experienced; the need to ensure that the woman has understood the implications of the method proposed, including injectable contraceptives, must be emphasised. For example, women, and their husbands if present, must be informed that amenorrhoea, irregular menstrual cycles and heavy bleeding occur to large numbers of injectable contraceptive users, that some women may gain weight, and that return to fertility may be slower than in the case of other contraceptives. Counselling sessions must also make women feel supported in case side effects are experienced, and emphasise the appropriateness of follow-up visits and phone calls in case the woman has concerns. Our finding that continuation rates were significantly higher among women who were provided comprehensive counselling underscores the critical role that health care providers play in ensuring method satisfaction.

\section{Make special efforts to inform injectable contraceptive users and potential users about health-related side effects}

Menstrual disturbances and weight gain are common and well-known side effects of injectable contraceptives, and return to fertility is typically longer among women who discontinue using injectable contraceptives than other methods. Women considering use of the method must be supported in making an informed decision, given these three key concerns. Irregular prolonged bleeding, amenorrhoea and/or heavy bleeding occur among most users of injectable contraceptives at some point while using the method, and women should be informed 
about this likelihood and the fact that side effects are typically not harmful. Although injectable contraceptives are a reversible method of fertility regulation, women also need to be informed that since the method is longacting, it cannot easily be discontinued or removed from the body if a complication occurs or if pregnancy is desired. Counselling sessions should be supplemented by pamphlets and easy-to-read materials that highlight these side effects, emphasise that they are not harmful, and advise users about the action to take in case they are experienced.

\section{Reduce barriers to accessing supplies}

Findings have shown that 16 percent of all women who had discontinued using injectable contraceptives and between 12 percent and 28 percent of women who had discontinued using the method after various doses reported difficulty in accessing re-supplies. The leading access-related barrier was the inconvenience of accessing the facility every three months for re-injections. Long distances, limited freedom of movement and unavailability of an escort, and time spent in travelling to the facility for re-injections were significant deterrent to method continuation. Efforts are needed that enable women to obtain re-injections closer to their homes and at reduced cost; the introduction of the method into the programme would go a long way in doing so.

\section{Conclusion}

In short, findings suggest that there is a demand for injectable contraceptives among women, and that both women and health care providers perceive a number of advantages associated with the method. As is well known, injectable contraceptives may not suit the lifestyle of many Indian women and our findings have confirmed that the method was adopted and was continued for one year or more, by relatively few women. Nevertheless, the fact that it was adopted by one in ten women seeking contraception, and was continued for one year or more by one in five women who adopted the method, reiterates that for a significant minority of women, its advantages exceed its disadvantages on balance. We conclude that there is indeed a demand for the method among this minority of women, and that the inclusion of injectable contraceptives in the basket of methods offered under the national programme, along with appropriate emphasis on health care provider training and on ensuring informed choice, will expand women's contraceptive choices and help in ensuring their reproductive rights. 


\section{Introduction}

\section{Rationale}

Injectable contraceptives are associated globally with low failure rates but lower 12-month continuation rates than such other methods as the oral contraceptive pill and intrauterine contraceptive device (IUCD) (Vaughan et al., 2008; World Health Organization, 2010; Ali and Cleland, 2010). Injectable contraceptives, notably depot medroxyprogesterone acetate (DMPA) and norethisterone enanthate (NET-EN), have been approved for commercial sale in India by the Drugs Controller General of India (Family Health International, 2010; Parivar Seva Sanstha, 2004; Indian Council of Medical Research, 2008). However, injectable contraceptives have not been provided in the basket of contraceptive methods available under the Reproductive and Child Health programme in India, largely because of fears expressed about their appropriateness for women in India and the quality of services (Parivar Seva Sanstha, 2004; Sarojini and Murthy, 2005). As such, injectable contraceptives are available only through private or social marketing channels. As a result, the use of injectable contraceptives is limited. Indeed, just 0.1 percent of married women in India were using injectable contraceptives in 2005-06 (International Institute for Population Sciences and Macro International, 2007).

Although injectable contraceptives have increasingly been offered by private and NGO facilities, including through the facilities of a number of health-serving NGO programmes [for example, the Family Planning Association of India (FPAI),
Janani, Parivar Seva Sanstha (PSS), and Population Health Services (India) (PHSI)], evidence of users' experiences is sparse. Indeed, a search revealed that very few studies have focused on the experiences of women using injectable contraceptives (see for example, Caleb-Varkey et al., 1998; Indian Council of Medical Research, 1985; 1990; 2008; United Nations Population Fund, India, 2004; Sama, 2003); while all of these explored menstrual disturbances, such issues as method continuation, method switching and acceptability, quality of services and provider perspectives on injectable contraceptives were infrequently assessed. This lack of evidence makes it difficult to evaluate the effectiveness, safety and acceptability of the method; inform the debate about the feasibility of including injectable contraceptives in the programme, and provide appropriate counselling for women to enable them to evaluate various contraceptive options and make an informed choice about which contraceptive method to adopt.

\section{Study Objectives}

The objective of this report is to shed light on the feasibility and acceptability of making injectable contraceptives more widely available to women in India. It does so from three perspectives. First and foremost, it assesses the experiences of injectable contraceptive users, including use histories, discontinuation and switching and factors underlying discontinuation; side effects experienced and the acceptability of these side effects; the quality of care received, including whether the counselling and information provided were comprehensive and 
follow-up appropriate, and the overall acceptability of the method. Second, it assesses the extent to which new method adopters opt for the injectable contraceptive method and their motivations for preferring injectable contraceptives or other methods. Third, it sheds light on the perspectives of providers of reproductive health services located in facilities providing injectable contraceptives, specifically with regard to the extent to which they recommend the method to their clients, the kind of counselling and information they provide, their perceptions about the experiences of their clients, and the extent to which they would advocate the inclusion of injectable contraceptives in the public health programme.

\section{Background}

Depot medroxyprogesterone acetate (DMPA) and norethisterone enanthate (NET-EN) are progestinonly formulations that are injected intramuscularly, and work primarily by preventing ovulation and thickening cervical mucus (Ministry of Health and Family Welfare and United Nations Population Fund, India, 2005). They are associated with a failure rate of less than 0.3 percent with perfect use (correctly and consistently), and three percent with typical use (Trussell, 2007; World Health Organization, 2010). Although used by a tiny minority of contraceptive users in India, injectable contraceptives are globally the fourth most popular contraceptive method; indeed, it is estimated that more than 32 million women use the method globally (Lande and Richey, 2006) and that it is found to be safe and acceptable to women in many developing country settings. DMPA is the method used in India; it is supplied largely by nongovernmental organisations and the private sector.

Globally, evidence suggests that injectable contraceptives are associated with higher rates of discontinuation than other methods: for example, the United Nations report on levels and trends of contraceptive use suggests that 34 percent of oral contraceptive users compared to 46 percent of injectable contraceptive users had discontinued the method during the first 12 months of use (United Nations, 2006). Likewise, a recent study of data from 23 countries found wide variation across countries, but noted that on average, 36 percent of women using injectable contraceptives had discontinued using the method within 12 months, compared to 28-29 percent of users of oral contraceptive pills and condoms and nine percent of IUCD users (Ali and Cleland, 2010).

As mentioned earlier, few studies from India have explored the perspectives and experiences of women who have used injectable contraceptives. Available studies have addressed issues relating to injectable contraceptive use through both qualitative and quantitative designs. The single most consistent finding of these studies is the extent to which injectable contraceptives are associated with menstrual disturbances. A synthesis of findings from these studies suggests that three-quarters or more women reported menstrual disturbances. For example, a multi-centric study of DMPA users in Ahmedabad, Vadodara and Hyderabad observed that 19 percent experienced excessive bleeding, 21 percent experienced irregular bleeding or spotting, seven percent reported scanty bleeding and 13 percent reported amenorrhoea (United Nations Population Fund, 2004). A second multi-centric study, covering 1209 women who were using NET-EN, reported that just 19 percent of those observed for the first six months of use reported no menstrual disturbance; in contrast, eight percent, 52 percent and 20 percent reported frequent bleeding, infrequent bleeding and amenorrhoea, respectively (Indian Council of Medical Research, 2008). In another study, conducted in Gujarat, 87 percent of DMPA users reported side 
effects, most of which were menstrual disturbances (Population Council, 2003). Side effects were also found to be widespread in a study conducted in Uttar Pradesh among 662 DMPA users: at six months, 68 percent reported side effects, mainly amenorrhoea (36\%), scanty periods and spotting (22\%) and excessive menstrual discharge (7\%) (Caleb-Varkey et al., 1998). This finding was also observed in a study of 80 women who had adopted injectable contraceptives from a facility in Karnataka: 65 percent experienced amenorrhoea and 70 percent experienced spotting (Rai, Prabakar and Nair, 2007). A study that compared monthly and bimonthly injections of two preparations of Norethisterone Enanthate among two groups of women found that the side effects reported at 12 months were bleeding-related (12-15\%) and amenorrhoea (4-7\%) (Indian Council of Medical Research, 1990). Likewise, a qualitative follow-up of 50 DMPA users in Delhi found that 25, 16 and 12 women had experienced amenorrhoea, excessive bleeding and irregular bleeding, respectively (Sama, 2003). Studies have noted that menstrual disturbances, notably amenorrhoea, increased over time: while 61 percent of DMPA users experienced menstrual disturbances overall, percentages ranged from 77 percent after the first dose to 90 percent among those who continued to use the method for 10 or more doses (Parivar Seva Sanstha, 2004). Other side effects reported by women in these studies included weight gain, pain, vaginal discharge, hot flushes and weakness (Sama, 2003; Caleb-Varkey et al., 1998; United Nations Population Fund, India, 2004; Parivar Seva Sanstha, 2004).

Internationally, discontinuation rates associated with injectable contraceptives range from 44 percent (World Health Organization, 2010) to 56 percent (Vaughan et al., 2008) at 12 months. Discontinuation rates observed among the few studies in India that have addressed this issue vary considerably. Two Indian studies report discontinuation rates similar to those observed in the international literature. For example, in 2005-06, the 12-month discontinuation rate among injectable contraceptive users was 53 percent in India (we note that the overall percentage of women who had used injectable contraceptives was just $0.1 \%$ ), compared to 20 percent among women using the IUCD and 49 percent among those using oral contraceptive pills (International Institute for Population Sciences and Macro International, 2007). The two multicentric studies that followed women up to 12 and 24 months, observed that 35-44 percent had discontinued use of NET-EN by 12 months (Indian Council of Medical Research, 1990; 2008). In contrast, other studies noted considerably higher discontinuation rates. For example, the study of injectable contraceptive users in various settings of Uttar Pradesh found discontinuation rates as high as 56 percent and 71 percent after the first and second dose of DMPA, that is, by three and six months, respectively (Caleb-Varkey et al., 1998), the assessment of DMPA clients of two NGOs observed that as many as 70-80 percent had discontinued use at 12 months (Parivar Seva Sanstha, 2004), and the facility-based study of DMPA clients in Karnataka reported a discontinuation rate of 43 percent at six months (Rai, Prabakar and Nair, 2007).

Notwithstanding widespread side effects and high rates of discontinuation, the injectable contraceptive method was acceptable to many (70-79\%), as reported in two studies that explored acceptability (United Nations Population Fund, India, 2004; Indian Council of Medical Research, 2008).

Two studies have addressed the quality of care received by injectable contraceptive users. Their findings suggest that women were not appropriately screened (Sama, 2003) and were not 
given information about the possible side effects and what to do in case of side effects (Population Council, 2003; Sama, 2003). For example, in urban Gujarat, just 28 percent of 184 DMPA clients were informed about the possible side effects of injectable contraceptives and 22 percent about what to do in case of side effects (Population Council, 2003).

In summary, in India, very few studies have focused on injectable contraceptive use. Almost all of these were conducted in the 1990s and early 2000s and suggest varying but low levels of method continuation, widespread experience of menstrual disturbances, and poor counselling and quality of services. Notwithstanding these findings, women in a couple of studies reported that injectable contraceptives were a convenient and acceptable method in principle.

\section{Study Setting}

Given the low prevalence of injectable contraceptive use in India, a community-based study was not feasible. The study therefore followed up injectable contraceptive users drawn from the facilities of a range of reproductive health NGOs, including the Family Planning Association of India, Janani, Parivar Seva Sanstha and Population Health Services (India). The facilities were drawn from both urban and periurban areas of several states, namely, Bihar, Delhi, Jharkhand, Madhya Pradesh and Maharashtra, and were selected purposively on the basis of the volume of injectable contraceptive users served by each clinic in the two years preceding the study. As mentioned earlier, the injectable contraceptive DMPA, approved by the Drugs Controller of India, is the method used in India and, as such, was the injectable contraceptive offered to women in our study.

The socio-demographic and reproductive health indicators of the study states, presented in
Table 1.1, highlight the well-known differences in socio-demographic indicators between such less developed states as Bihar, Jharkhand and Madhya Pradesh on the one hand, and better developed ones such as Delhi and Maharashtra on the other. For example, female literacy rates ranged from 53-60 percent in the less developed states to 76-81 percent in the better developed ones; the total fertility rate ranged from 3.1-4.0 in Bihar, Jharkhand and Madhya Pradesh to 2.1 in Delhi and Maharashtra; the infant mortality rate ranged from 28-30 in Delhi and Maharashtra to 42-62 in Bihar, Jharkhand and Madhya Pradesh; and the percentage of women reporting skilled attendance at delivery ranged from 28-33 percent to 64-69 percent in these states, respectively.

The pattern was somewhat different with regard to other indicators. The child sex ratio varied widely between study states. It was far below the national average in Delhi and Maharashtra, well above it in Bihar and Jharkhand, and similar to the national average in Madhya Pradesh. Contraceptive use patterns also varied. Overall contraceptive prevalence ranged from 34-36 percent in Bihar and Jharkhand to 56 percent in Madhya Pradesh and 67 percent in both Delhi and Maharashtra. A similar pattern emerged with regard to the unmet need for contraception, which ranged from 23 percent in Bihar and Jharkhand to 8-11 percent in Delhi, Madhya Pradesh and Maharashtra. Use of modern non-terminal methods was, for the most part, limited: it ranged from 5-7 percent in Bihar, Jharkhand and Madhya Pradesh, to 12 percent in Maharashtra and 33 percent in Delhi. Awareness of injectable contraceptives among both women and men was considerably more widespread in Delhi than in any other state: 81 percent versus 33-66 percent among women, and 69 percent versus $38-48$ percent among men. 


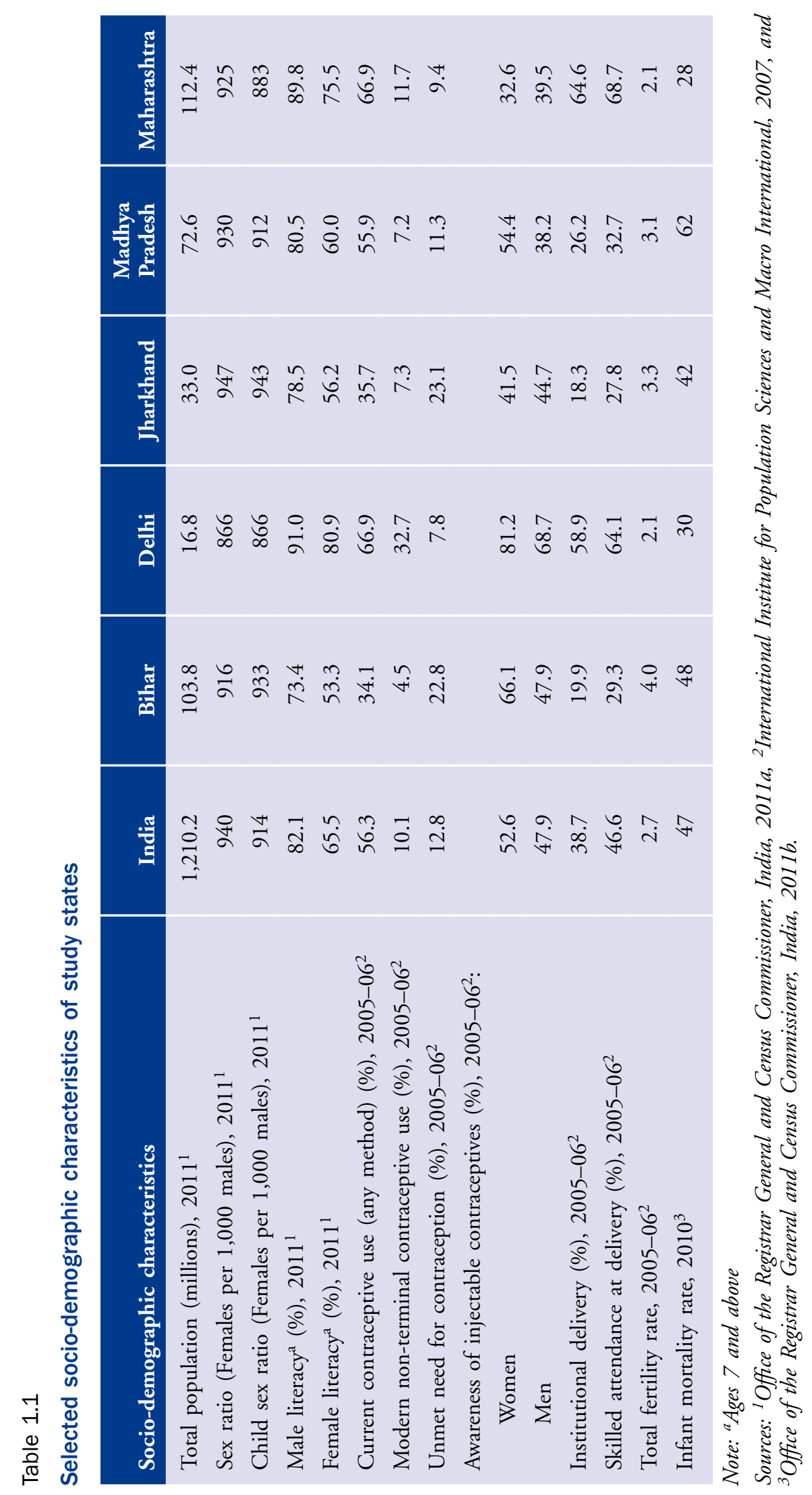




\section{Study Design}

As described above, the study was conducted in selected facilities of various reproductive health NGOs in India. From these NGOs, a total of 27 facilities were selected purposively on the basis of their records of first-time injectable contraceptive clients served during the calendar year 2010. More specifically, we perused the monthly reports of all NGOs and selected those facilities that reported an average of 25 or more first-time injectable contraceptive clients over the period March to September 2010. The study included three components, namely, a survey of first-time injectable contraceptive users, exit interviews with women seeking contraception, and in-depth interviews with contraceptive service providers from participating facilities.

\section{Survey of injectable contraceptive users: A} retrospective study design was employed in which women who had initiated injectable contraceptive use any time during March to September 2010, at least 12 months prior to the interview in the participating facility, were followed up, to assess their experiences with the method. While a prospective design has many advantages, for example that it enables researchers to obtain experiences on the day of method adoption and at regular intervals thereafter, and consent procedures are simpler, it is more timeconsuming and costly. Hence, a retrospective design was used. In order to assess use patterns, a calendar was employed that recorded women's monthly family planning use and pregnancy status/outcomes between January 2009 (prior to the adoption of injectable contraceptives) and the month of interview, thereby covering the periods prior to and following the initiation of injectable contraceptive use.

Exit interviews with women seeking contraception: A survey of women seeking contraception was fielded that assessed, through exit interviews, women's awareness of injectable contraceptives, the method selected and reasons underlying acceptance or nonacceptance of injectable contraceptives.

In-depth interviews with health care providers: In-depth interviews with health care providers were conducted to draw out provider perspectives about the advantages and disadvantages of injectable contraceptives, the experiences of women using injectable contraceptives, and the kinds of counselling and follow-up provided to women who adopted injectable contraceptives.

\section{Study samples and coverage}

Samples for all three components of the study were drawn from among the clients and providers of the 27 selected facilities. Details are provided in

Table 1.2.

Survey of injectable contraceptive users: Our study design called for a sample size of 360 women who had initiated injectable contraceptive use during the recruitment period, roughly 12-21 months prior to the interview. This number includes inflation to take into account a cluster effect, which we assumed to be 20 percent. Further, given that the address or telephone number provided by many clients to the clinic may have been incomplete, inaccurate or obsolete (as we were following up on clients who had visited the clinic at least 12 months prior to the survey), we recognised that follow-up of all listed women was unlikely and unrealistic. Indeed, going by the experience of previous follow-up studies and by personal communications with the NGOs providing services, we assumed that as a result of loss to follow-up, and, to a much lesser extent, refusal to participate in the study, we would be able to interview no more than one half to two-thirds of clients who had adopted the injectable contraceptive 
Table 1.2

\section{Coverage of the study}
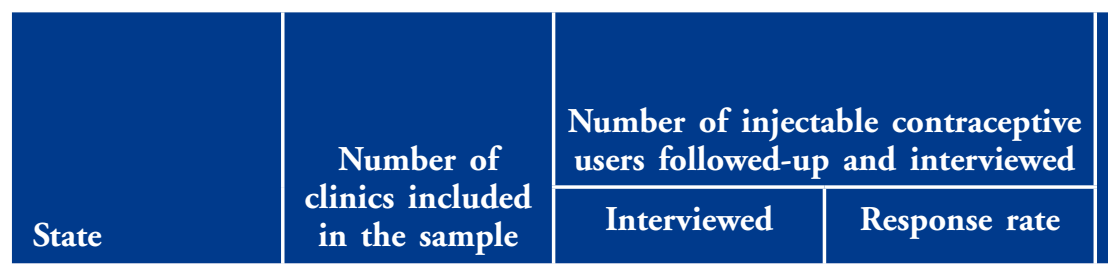

Number of
women seeking
contraceptive
services who
participated in
exit interviews

Number of in-

depth interviews

with health care

providers

Bihar

12

94

50.5

45

43.0

Delhi

1

99

60.7

Madhya Pradesh

108

52.3

Maharashtra

3

23

50.0

Total

27

375

50.7

34

14

4

20

117

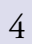

1

5

2

4

16 method 12 or more months prior to the interview. Hence, we aimed to make efforts to reach at least 600 clients in order to ensure a total of at least 360 interviewed women.

The 27 selected facilities yielded a total of 740 women who had adopted injectable contraceptives between 12 and 21 months prior to the survey and whose addresses appeared to be complete. Efforts were made to reach all of these 740 women, and all those contacted were invited to participate in the study. Respondents thus included both those who were still using the method at the time of interview, as well as those who had discontinued the method and were either not using any method, had switched to another method, or had taken a break and returned to using injectable contraceptives by the time of the survey. A total of 375 women were successfully interviewed, giving a response rate of 51 percent. The majority of women $(82 \%)$ were interviewed in their home; a few, 10 percent and eight percent, were interviewed telephonically and at the facility, respectively.

\section{Exit interviews with women seeking contraception:}

In a secondary component of the study, we interviewed women who sought contraceptives from the 27 facilities from which our sample of women who had adopted injectable contraceptives was drawn. For this component of the study, interviewers spent two to three days in each facility and interviewed all the women who sought contraception from that facility, irrespective of the method adopted. The exit interviews sought to understand the extent to which the health care provider had offered the woman the injectable contraceptive method, factors underlying the adoption of the method finally selected, and, more specifically, why the injectable contraceptive method was or was not adopted. A total of 117 women who sought contraceptive services from the study facilities and who agreed to be interviewed participated in the exit interviews.

\section{In-depth interviews with health care providers:} In-depth interviews were held with at least one health care provider from each study facility who had provided injectable contraceptive services to at least 25 women in the 12 months preceding the study. A total of 16 in-depth interviews were thus conducted, each lasting one to two hours. 


\section{Data collection}

Data collection for all three components of the study was conducted simultaneously and took place between June and November, 2011. Two structured instruments were used to collect data from injectable contraceptive users, and women seeking contraceptive services from study facilities. In-depth interview guidelines were used to interview health care providers. Almost all interviews were held face-toface; some 36 injectable contraceptive users opted for a telephonic interview.

The questionnaire for injectable contraceptive users was designed to gather background information of the women as well as their contraceptive histories over the 36 months preceding the interview, a period that also covered the 12-21 month period following the adoption of injectable contraceptives. As such, a calendar was employed, that obtained information month-wise about method use, discontinuation, method switching, and, if pregnancy occurred, its date and outcome. Aside from this, the interview probed women's decision-making process, side effects experienced and the acceptability of these side effects, reasons for discontinuation, the perceived acceptability of injectable contraceptives, the quality of care received, including whether counselling and information provided were comprehensive and follow-up appropriate, factors that posed obstacles to the continuation of the injectable contraceptive method, and, for those who had experience with other contraceptive methods, their assessment of the relative advantages and disadvantages of the injectable contraceptive method.

The exit interview questionnaire also obtained background information of women seeking contraceptive services, but focused on a few issues, namely, the method adopted on the day of interview and other methods that may have been used in the past; information provided by the health care provider on various methods of contraception; factors underlying the final choice of method, and specifically for choosing or not choosing the injectable contraceptive method, and the quality of care that they had received.

Guidelines for in-depth interviews addressed such issues as provider perspectives about injectable contraceptives; their suitability for different groups of women; the experiences of clients who had used injectable contraceptives, notably with regard to duration of use, side effects and menstrual disturbances experienced; severity of and action taken for side effects, and the experiences of clients who had adopted injectable contraceptives versus other contraceptive methods. We also probed aspects of quality of care, including, for example, the kind of information that they provided to women seeking contraceptives, and recommendations on the advisability of including injectable contraceptives in the basket of methods provided in the public health system.

A team of five female interviewers and three male coordinators conducted the interviews. While the male coordinators did not conduct interviews with women, they tracked respondents, facilitated contact between respondents and interviewers, and conducted in-depth interviews with health care providers. Investigators underwent a three-day training programme that comprised a combination of classroom sessions and mock interviews. Training focussed on interviewing methods, the details of the questionnaire, and research ethics, with particular reference to this study, and the need to maintain confidentiality.

The study instruments were prepared in English, translated into Hindi, and pre-tested. In-depth interviews were taped, transcribed and translated into English. 


\section{Analysis}

Data from the survey of injectable contraceptive users and of women seeking contraceptive services were entered in CSPro 4.0 and analysed using PASW statistics 18. Analysis is largely descriptive. Life table techniques were used to derive injectable contraceptive continuation and discontinuation rates. As such, segments of use were employed as units of analysis in the construction of the life table for discontinuation. A segment is an uninterrupted period of use of the method. The life table technique allows for the inclusion of both complete and incomplete segments (for example, those continuing to use the method at the time of interview) of use in an analysis and are considered to be the most appropriate way of assessing the continuity of contraceptive use (Trussell and Kost, 1987). Segments of use are divided into monthly intervals, measured from the time of beginning the segment. The construction of life tables for discontinuation rates, for example, starts with the calculation of month-by-month discontinuation rates. These rates are then linked together to obtain a cumulative continuation or discontinuation rate over a period of time. Although our calendar collected histories from January 2009, continuation rates have been calculated for the first segment of injectable contraceptive use, that is, from the month in which injectable contraceptives were adopted (March to September, 2010) to the month of interview (June to September, 2011). Hence, for example, only the first segment of use is considered for women who discontinued using the method and then initiated it again after some time.

We also compared factors underlying the continuation of injectable contraceptive use among women who had used the method for at least nine months with those who had discontinued using the method before that time. Multivariate logistic regression analysis was conducted to ascertain the relationship between injectable contraceptive continuation and a range of socio-demographic and use-related factors.

For textual data, a coding scheme was developed and transcripts were coded in ATLAS.ti 6.0 using this coding scheme. The coded blocks of text related to specific themes, for example, negative and positive features of injectable contraceptives, side effects experienced by clients, content of counselling provided to users and potential users, and recommendations for the inclusion of injectable contraceptives in the national programme. These blocks were analysed to capture typical patterns.

\section{Ethical issues and consent procedures}

We recognised that in both the survey of injectable contraceptive users and of women seeking contraception in the selected facilities, serious ethical concerns arose. Primary among these was the fact that women's right to confidentiality could be violated if the researchers approached women directly. Hence, the research team did not make the initial follow-up contact with women in both surveys. In the case of women who had adopted injectable contraceptives 12-21 months earlier, it was a staff member of the facility from which the woman had obtained her injectable contraceptive supplies who made the initial contact. It was the responsibility of the facility staff member to describe the study-its objectives and procedures - to the client, emphasise that neither abortion nor any other services would be affected and seek initial consent from the woman. In the case of the facility-based component, the clinic administrator obtained initial consent from all women seeking contraception to permit a study interviewer to approach them. Once initial consent was provided, a research team member approached the client, sought consent once 
more, and made an appointment to interview her at a suitable time and place. Once consent was thus obtained, the woman was recruited into the study and interviewed. In contrast, a research team member shared a detailed consent form with health care providers and sought their written consent for participating in in-depth interviews.

The study was approved by the Ethics Committee of the Family Planning Association of India.

\section{Structure of this report}

This report has five main sections apart from this introductory chapter. Chapter 2 describes the sociodemographic characteristics of respondents. Chapter 3 addresses the perspectives and experiences of women who had adopted injectable contraceptives 12-21 months prior to the interview; it focuses on such issues as method discontinuation and switching, side effects experienced, reasons for discontinuation and method acceptability. Chapter 4 addresses the perspectives and experiences of women seeking contraception at study facilities; it focuses on the method selected and factors influencing the adoption of injectable contraceptives or other non-terminal methods. Chapter 5 documents the perspectives of health care providers, their perceptions of their clients' experiences, the extent to which they encourage or dissuade their clients from adopting injectable contraceptives, and their recommendations about incorporating injectable contraceptives in the national programme. Chapter 6 summarises the findings of this study and offers programmatic recommendations with regard to women's experiences and perspectives on expanding access to injectable contraceptives. 


\section{Social and demographic characteristics of respondents}

This chapter presents the socio-demographic profile of respondents, including both women who had adopted injectable contraceptives 12-21 months prior to the survey, and those seeking to adopt contraception at study facilities during the period of the survey.

Table 2.1 presents the socio-demographic characteristics of respondents. While most indicators are simple percentages, we note that household economic status was measured using an index, composed of household asset data on the ownership of selected durable goods and access to amenities; the index was adapted from the household standard of living index used in the Youth in India: Situation and Needs study (International Institute for Population Sciences and Population Council, 2010). The index was constructed from the following items, with scores assigned as follows: source of lighting ( 2 for electricity, 1 for kerosene, solar light, and 0 for others); source of drinking water (2 for piped water, hand pump, covered well, etc; 0 for others); toilet facility ( 3 for flush toilet, 2 for pit toilet or public toilet, and 0 for no facility); 2 each for the ownership of a television, refrigerator or land/mobile phone, and 0 for none. Scores were cumulated; the index therefore ranges from 0 to 13 .

Among the 375 women who had used injectable contraceptives, Column 2 of Table 2.1 shows that 82 percent of all respondents were Hindu and 22 percent belonged to scheduled caste or tribe households. Respondents were, on average, 29 years old. They were relatively well educated: for example, while about one-quarter (26\%) had never been to school, more than one-third had completed high school (36\%). Women who had adopted injectable contraceptives reported an average score of 9.8 on the wealth index (of a maximum of 13). Work profiles suggest, moreover, that just 16 percent were engaged in wage-earning activities. Almost half of all women, 48 percent, resided in nuclear families and four percent reported that their husband lived away from them for extended periods of time. As far as fertility levels are concerned, injectable contraceptive users had an average of 2.6 surviving children, with two-fifths reporting three or more surviving children.

Among the 117 women seeking to adopt contraception (Column 3 of Table 2.1), profiles were largely similar. Among this group, 80 percent were Hindu and 20 percent belonged to scheduled caste or tribe households. On average, respondents were aged 28 years, more than two-fifths (44\%) had never been to school, and just 12 percent were engaged in wage-earning activities. As far as household economic status was concerned, the average score on the wealth index was 8.5 (of a maximum of 13). More than two-fifths (44\%) resided in nuclear families and five percent reported that their husband lived away from them for extended periods of time. As far as fertility levels are concerned, women seeking to adopt contraception had an average of 2.9 surviving children, with almost three in five reporting three or more surviving children. 
Table 2.1

Socio-demographic profile of respondents

\begin{tabular}{|c|c|c|}
\hline Socio-demographic characteristics & $\begin{array}{l}\text { Women who had adopted } \\
\text { injectable contraceptives, } \\
\text { March-September, } 2010\end{array}$ & $\begin{array}{l}\text { Women seeking to adopt } \\
\text { contraception, } \\
\text { June-September, } 2011\end{array}$ \\
\hline Number of women & 375 & 117 \\
\hline Age of women (years) (Mean) & 28.7 & 27.9 \\
\hline Education (\%) & & \\
\hline No education & 25.9 & 43.6 \\
\hline Completed Class 10 or higher & 36.0 & 18.8 \\
\hline Religion (\%) & & \\
\hline Hindu & 82.4 & 79.5 \\
\hline Muslim & 14.4 & 18.8 \\
\hline Other & 3.2 & 1.8 \\
\hline Caste $(\%)$ & & \\
\hline Schedules castes & 12.0 & 16.2 \\
\hline Scheduled tribes & 9.9 & 3.4 \\
\hline Other backward castes & 48.5 & 54.7 \\
\hline General & 29.6 & 25.6 \\
\hline Work status $^{\mathbf{a}}(\%)$ & & \\
\hline Worked for wages in the last year & 16.3 & 12.0 \\
\hline Wealth index (0 to 13) (Mean) & 9.8 & 8.5 \\
\hline Family type (\%) & & \\
\hline Nuclear: Co-resides with husband/children only & 47.5 & 44.4 \\
\hline $\begin{array}{l}\text { Extended/Joint: Co-resides with husband and/or } \\
\text { other family members }\end{array}$ & 48.3 & 50.4 \\
\hline $\begin{array}{l}\text { Extended/Joint: Lives with other family members, } \\
\text { but husband lives away for extended periods of } \\
\text { time }\end{array}$ & 4.3 & 5.1 \\
\hline Total number of surviving children ${ }^{a}(\%)$ & & \\
\hline 0 & 0.8 & 1.7 \\
\hline 1 & 18.1 & 6.0 \\
\hline 2 & 41.1 & 34.2 \\
\hline 3 or more children & 40.0 & 58.1 \\
\hline Mean & 2.56 & 2.86 \\
\hline State $(\%)$ & & \\
\hline Bihar & 25.1 & 40.2 \\
\hline Delhi & 26.7 & 29.1 \\
\hline Jharkhand & 28.8 & 10.3 \\
\hline Madhya Pradesh & 6.1 & 3.4 \\
\hline Maharashtra & 13.3 & 17.1 \\
\hline Total & 100.0 & 100.0 \\
\hline
\end{tabular}

Note: ${ }^{a}$ At the time of accepting the first dose of injectable contraceptives among women who adopted injectable contraceptives during March-September, 2010 and were interviewed retrospectively, and on the day of the interview for women seeking contraception. 
We note, finally, that our state-wise distribution of respondents varied considerably as a result of our purposive sampling design. More than three-quarters of both injectable contraceptive users and women seeking contraceptive services came from three states-Bihar, Jharkhand and Delhi.

The socio-demographic profile of the 16 health care providers interviewed in-depth shows that all 16 were female. They ranged in age from 30 to 78 years, with four health care providers aged between
30 and 39 years, six each aged between 40 and 49 years and 50 years and above. As far as educational qualifications are concerned, 14 held MBBS degrees, and two held BAMS (Bachelor of Ayurvedic Medicine and Surgery) degrees. Finally, most health care providers had been practising for extended periods of time. Indeed, the median number of years during which health care providers had been practising was 22 years, ranging from four to 37 , with just four health care providers reporting that they had been practising for less than ten years. 


\section{Experiences of women using injectable contraceptives}

This chapter explores the experiences of women who had adopted injectable contraceptives 12-21 months prior to the study. It covers a range of issues: their sources of information about injectable contraceptives prior to adopting the method and the decision-making process leading to injectable contraceptive use; the duration of use and reasons for discontinuation; side effects experienced, their severity, and action taken to address them; method switching experiences; and acceptability of the method, namely, perceptions about its best and worst features.

As mentioned earlier, our sample comprised women who had adopted injectable contraceptives during the period March to September 2010, such that the vast majority of women had adopted the method 12-21 months prior to the interview, although, in a few cases, adoption had taken place 16-21 months prior to the interview. Almost all women who had adopted the method (95\%) reported that they were issued a card at the time of getting the first dose of injectable contraception; however, only one quarter $(27 \%)$ of women were able to locate the card and present it to the interviewer.

\section{Decision-making process}

Women who had adopted injectable contraceptives were probed about the source from which they had first heard about injectable contraceptives-whether prior to adoption of the method or in the course of seeking contraceptive services. Findings, presented in Table 3.1, suggest that the majority of women had heard about injectable contraceptives from a health care provider or facility (62\%), either in the course of seeking contraceptive services, or in the course of a previous visit. As many as 46 percent of the women had been informed about the method by a private sector provider. It is notable, however, that although the method is not available through the public sector, as many as one in five women reported having heard about injectable contraceptives from a public sector provider, and specifically a nurse or Auxiliary Nurse Midwife (ANM) (15\%) and an ASHA (Accredited Social Health Activist) or AWW (Anganwadi Worker) (5\%). In addition to health care providers, a large proportion $(47 \%)$ of women reported that they had heard about the method from their informal networks, most often a friend or neighbour (30\%) and/or their husband (10\%).

Women were asked, in addition, about which contraceptive method or methods they had wanted to adopt when they visited the facility to obtain contraceptive services. As Table 3.2 suggests, twothirds of all injectable contraceptive users had planned to adopt injectable contraceptives when they arrived at the facility for contraceptive services 12-21 months earlier, clearly suggesting that many women had come to the facility with some prior awareness of the method. Nevertheless, about 16 percent of all injectable contraceptive users had originally 
Table 3.1

Source of information among women who had adopted injectable contraceptives: Percentage of women who had heard about injectable contraceptives prior to or in the course of seeking contraceptive services by source of information

\begin{tabular}{l|c} 
Source of information & $\begin{array}{c}\text { Women who had adopted } \\
\text { injectable contraceptives }\end{array}$ \\
\hline Health care provider/facility & $\mathbf{6 2 . 4}$ \\
Private doctor/Clinic & 45.6 \\
Public sources & 20.3 \\
Primary Health Centre & 0.8 \\
Community Health Centre & 0.3 \\
Nurse/ANM & 14.7 \\
ASHA/AWW & 5.3 \\
Family, friends and neighbours & 46.7 \\
Family members & 19.5 \\
Husband & 10.1 \\
In-laws/Parents & 2.4 \\
Other relatives (aunt/sister-in-law/sister/other) & 7.5 \\
Friend(s) and neighbour(s) & 29.9 \\
Other & \\
Public campaigns (poster/radio/vehicle announcement) & \\
Number of women & 1.1 \\
\hline
\end{tabular}

Note: Multiple responses possible.

intended to adopt a different method: nine percent had intended to be sterilised and seven percent to adopt a different non-terminal method-six percent to have an IUCD inserted, and about two percent to use oral contraceptives or the condom. Almost one-fifth (19\%) were undecided about which method to adopt when they visited the facility. Among the 16 percent who had visited the facility intending to adopt a specific method other than injectable contraceptives, the health care provider had played a key role in influencing the adoption of injectable contraceptives: one half of these women reported that the health care provider had counselled them and suggested that the method they had intended to adopt was not appropriate for them (50\%; not shown in table). In a few cases, the woman and/ or her husband had changed their mind after being counselled: 12 percent reported that they were afraid of the side effects of the method they had originally selected, and eight percent reported that their husband did not permit her to adopt the method they had intended to use (not shown in table).

Table 3.3 presents the role of the woman herself and others in the final decision to adopt injectable contraception. It is notable that the large majority of women $(86 \%)$ reported that they had made the final decision to adopt injectable contraceptives on their own, with or without the involvement of other 
Table 3.2

Intended contraceptive method: Percentage of women by contraceptive method they had intended to adopt prior to visiting the facility

\begin{tabular}{l|c|} 
Intended contraceptive method & $\begin{array}{c}\text { Women who had adopted } \\
\text { injectable contraceptives }\end{array}$ \\
\hline Injectable contraceptives & 66.7 \\
Other non-terminal methods & 6.9 \\
$\quad$ Intrauterine contraceptive device & 5.6 \\
Oral contraceptive pill & 1.3 \\
Condom & 0.3 \\
Terminal method & \\
$\quad$ Female sterilisation & 8.8 \\
Undecided: no method in mind & 19.2 \\
Number of women & $\mathbf{3 7 5}$
\end{tabular}

Note: Multiple responses possible; ${ }^{*} 64.8$ percent reported that they had intended to adopt injectable contraceptives and no other method.

decision-makers. Others participating in the final decision included the husband (63\%) and a health care provider (12\%); the mother-in-law and others were rarely involved. It is notable that just a little over one half $(52 \%)$ of all women reported that they had made the decision jointly with their husband; about 11 percent of the women reported that their husband had made the final decision without them.

Table 3.3

Contraceptive decision-making role: Percentage of women by lead decision-maker(s) in the final selection of injectable contraceptives

\begin{tabular}{l|c} 
Decision-maker & $\begin{array}{c}\text { Women who had adopted } \\
\text { injectable contraceptives }\end{array}$ \\
\hline Health care provider & $\mathbf{1 2 . 0}$ \\
Doctor & 11.2 \\
Nurse & 1.2 \\
Self & $\mathbf{8 5 . 6}$ \\
Other & \\
Husband & 62.7 \\
Mother-in-law & 1.3 \\
Friend, other & 0.8 \\
Nunber of women & $\mathbf{3 7 5}$
\end{tabular}

Note: Multiple responses possible; ${ }^{*} 52$ percent made the decision together with wife. 


\section{Injectable contraceptive counselling}

Women were asked about the kind of counselling they had received when they opted for injectable contraceptives. Findings, presented in Table 3.4, suggest that counselling was not comprehensive for most women. Almost all reported that they had been informed about the three-monthly cycle of injectable contraceptives and its cost $(98 \%$ and $91 \%$ respectively), 77 percent had been informed about how the method works, and two-thirds had received an information brochure on the method from the health care provider. However, fewer than one half had been counselled about other matters: for example, just 56 percent had been informed about the possible side effects of the method, 34 percent about what they should do if they encountered any problems or side effects, and 42 percent had been informed that they should return to the service provider or facility if they had any doubts or experienced any problem.
Also of concern was the finding that of those informed about side effects, relatively small proportions were informed about the range of side effects experienced, in general, by women using injectable contraceptives. Hence, as seen in Table 3.5, of the 148 women counselled about side effects, fewer than two-thirds (63\%) were told about the possibility of experiencing amenorrhoea, less than half about the possibility of experiencing heavy bleeding $(47 \%)$, and 35 percent about the possibility of experiencing irregular periods. Few women reported being told about other side effects: spotting (12\%), weight gain (16\%), backache (4\%) and weakness $(5 \%)$. Given the large proportion of women who experienced side effects, it is of concern that so few were informed about the links between injectable contraceptive use and menstrual disturbances, in particular.

\section{Table 3.4}

Injectable contraceptive counselling and information obtained from health care providers

Counselling and information

Access to written materials

Received a brochure on injectable contraceptives from the health care provider

Had seen a poster on injectable contraceptives at the facility

\section{Information provided about}

How injectable contraceptives work

The non-terminal nature of injectable contraceptives and need for three-monthly follow-up visits for repeat injections

Cost of each injection

Possible side effects of injectable contraceptives

Action to be taken if problems or side effects are encountered

Told to come back to the clinic or contact health worker if she has doubts/side effects

Number of women
All women

90.9

375 
Table 3.5

Information provided by health care providers about side effects: Percentage of women who were informed about possible side effects of injectable contraceptives by type of side effect discussed

\begin{tabular}{l|c}
\hline Side effects & Women who were informed about side effects \\
\hline Heavy bleeding & 46.6 \\
Spotting between menstrual periods & 12.2 \\
Irregular periods & 35.1 \\
Amenorrhoea & 62.8 \\
Backache & 4.1 \\
Weakness & 4.7 \\
Weight gain & 16.2 \\
Number of women & $\mathbf{1 4 8}$
\end{tabular}

\section{Side effects experienced}

Women were asked about the side effects experienced after taking each dose of the injectable contraceptive: a general question was first posed, asking women to spontaneously identify the side effects experienced, and this was followed by probing questions that inquired about the experience of any other side effects that may have been experienced. Table 3.6 (Column 2) presents women's experiences as reported both in direct questioning and after probing. Findings suggest that large proportions of users reported the experience of one or more side effects. In all, 82 percent reported one or more side effects that occurred following the first or subsequent doses of injectable contraceptives; three-quarters of these women $(74 \%)$ reported a side effect spontaneously (not shown in table). About three-quarters of all women $(76 \%)$ had experienced one or more menstrual disturbances: indeed, between one-fifth and two-fifths had experienced such disturbances as amenorrhoea, heavy bleeding and irregular periods. Further, almost all of these women reported menstrual disturbances spontaneously $(68 \%$; not shown in table).
Almost three in five women (58\%) reported experiences of other side effects related to the use of injectable contraceptives, including weakness (40\%), backache $(27 \%)$, weight gain $(16 \%)$ and anxiety or stress (15\%). A large proportion of women reporting such other side effects also did so spontaneously (38\%, not shown in table). We note that the majority of women who reported other side effects also reported one or more menstrual disturbances. Indeed, just 22 women (about 10\% of women reporting other side effects) did not also report menstrual disturbances. Of these 22 women, 13 reported weakness, six reported weight gain, four reported backache, three reported weight loss, two reported anxiety or stress and three reported swelling, pain and so on (not shown in table).

Columns 3 and 4 of Table 3.6 show the extent of side effects experienced by women who had discontinued after the first or second dose, and those who had continued for three or more doses of injectable contraceptives, respectively. Overall, similar proportions of women in both groups reported one or more side effects. Findings further show that while similar proportions of women 
in both groups had experienced one or more menstrual disturbances, women who continued using injectable contraceptives beyond the second dose were significantly less likely than shorter-term users to report such menstrual disturbances as heavy bleeding and irregular periods, and significantly more likely to have experienced amenorrhoea. Other side effects were slightly more likely to have been experienced by women who had discontinued using the method after the first or second dose compared to longer-term users; indeed, longer-term users were significantly less likely to report weakness, weight loss and anxiety or stress than shorter-term users, but were significantly more likely to report weight gain.

In order to assess the extent to which the experience of side effects diminished with subsequent doses of injectable contraceptives, we explored experiences after each dose among women who had continued to use the method for three or more doses. Findings show a mixed picture (Columns 5 , 6 and 7 of Table 3.6). The experience of menstrual disturbances fell consistently but mildly with continued use of injectable contraceptives-from 47 percent after the first dose to 35 percent after the third dose, with proportions experiencing such side effects as heavy bleeding declining significantly between the first and second doses, while the experience of amenorrhoea declined modestly. Experiences of other side effects suggest that overall, reporting of side effects increased significantly in the period between the first and second doses, and fell significantly thereafter, but experiences of individual side effects varied considerably. For example, there was a significant increase in the experience of weight gain, self-reported foul smelling vaginal discharge and swelling of feet and hands between the first and second doses, which then levelled off or declined marginally thereafter. At the same time, the experience of weakness and back pain increased more modestly between the first and second doses, and also levelled off thereafter.

In order to better understand the action taken by women who experienced various side effects, women who had experienced a particular side effect were asked whether they had complained about it to a health care provider. Findings reported in Table 3.7 suggest that overall, some 62 percent of all women, and 59-60 percent of those experiencing any menstrual disturbance or any other side effect, had brought their side effect to the attention of a health care provider. Among women experiencing different types of side effects, those who had experienced menstrual disturbances together with other side effects, and those reporting three or more side effects were most likely to have complained to a health care provider ( $80 \%$ and $84 \%$, respectively). In contrast, fewer women experiencing only menstrual disturbances $(32 \%)$, only other side effects $(27 \%)$ or fewer (one or two) side effects (44\%) reported that they had complained about their side effect(s) to a health care provider.

A roughly similar picture emerged when women were also asked whether the side effect(s) had affected their performance of regular household responsibilities, both in terms of physical inability to perform routine tasks and in term of the cultural proscriptions forbidding women to enter the kitchen, perform pujas or visit a place of worship during menstruation. Overall, half (52\%) of all womenranging from 40 percent of those experiencing some menstrual disturbances to 65 percent of those experiencing some other side effects-reported that the side effect had interfered with the performance of their regular household responsibilities. Women who experienced both menstrual disturbances and other side effects and those who experienced three or more side effects, were most likely to report 


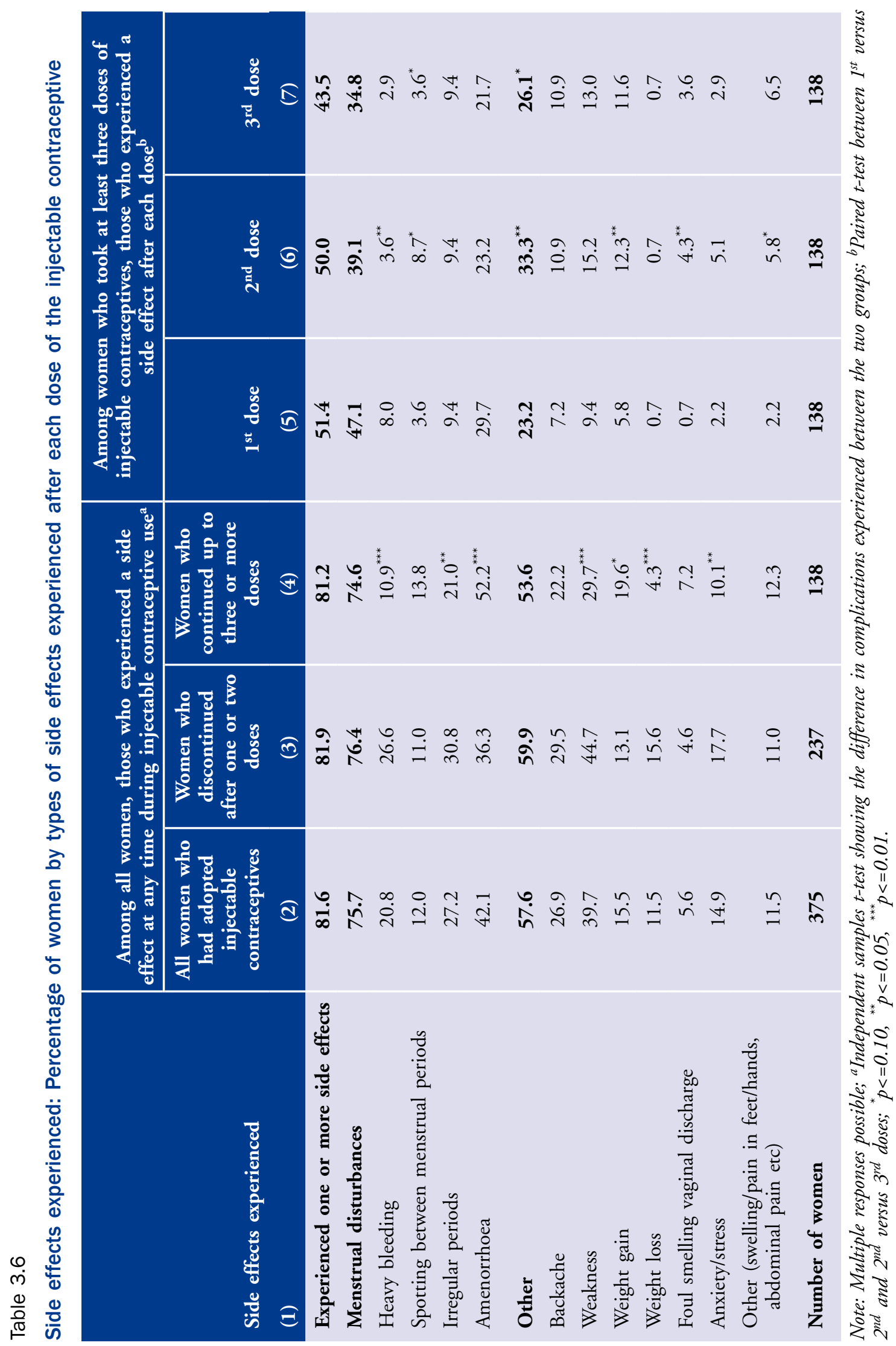


Table 3.7

Of women experiencing at least one side effect, percentages reporting that they had complained to a health care provider about the side effect and that the side effect had affected their ability to perform household work

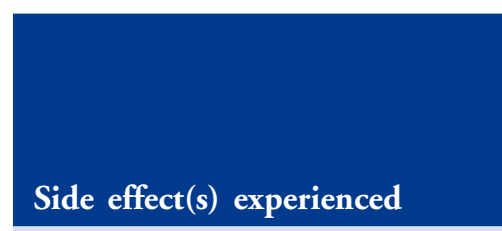

Any side effect

Any menstrual disturbance

Any other side effect (other than menstrual disturbance)

One or two side effects

Three or more side effects

\section{Specific side effects}

Only menstrual disturbances, no other side effects

Only other side effects, no menstrual disturbances

Both menstrual disturbances and other side effects

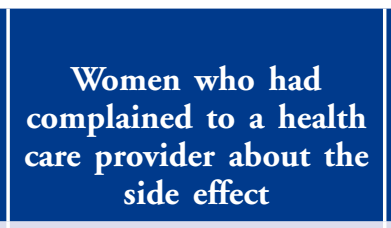

$\mathbf{6 2 . 4}$

58.8

59.7

43.9

83.8

32.2

27.3

80.4
Women whose side effect affected the performance of regular household responsibilities

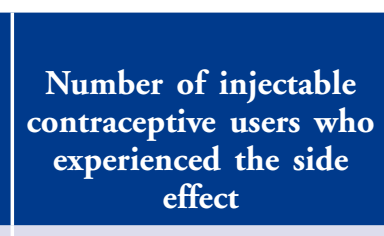

52.3

40.1

64.8

26.8

81.7

16.7

36.4

70.6
306

284

216

164

142

90

22

194

Note: Multiple responses possible.

that the performance of their regular household responsibilities had been affected. For example, 71 percent of those who experienced menstrual disturbances along with other side effects (most often backache, weakness and weight gain), and 82 percent of those who experienced three or more side effects, reported that the side effect had disturbed their performance of household responsibilities, compared to 17 percent of those who had experienced a menstrual problem without other side effects and 36 percent of the small number of women who had experienced some other side effect without any menstrual disturbances.

\section{Method continuation}

The study recruited women who had adopted injectable contraceptives for the most part, 12-15 months prior to the interview; a few women were included whose first dose of injectable contraceptives had been taken earlier, that is, 16-21 months prior to the interview. About one half of all women reported that they had taken just one dose of injectable contraceptives, and just one quarter reported taking four or more doses.

Life table method continuation rates were measured at the completion of the second, third, fourth and fifth doses, that is at six, nine, 12 and 15 months, respectively, and are presented in Figure 3.1. Findings confirm low rates of continuation. The continuation rate after six months was just 51 percent, and fell to 37 percent, 23 percent and 15 percent at nine, 12 and 15 months, respectively. 
Figure 3.1 Life table continuation rates of injectable contraceptives at the completion of each tri-monthly dose

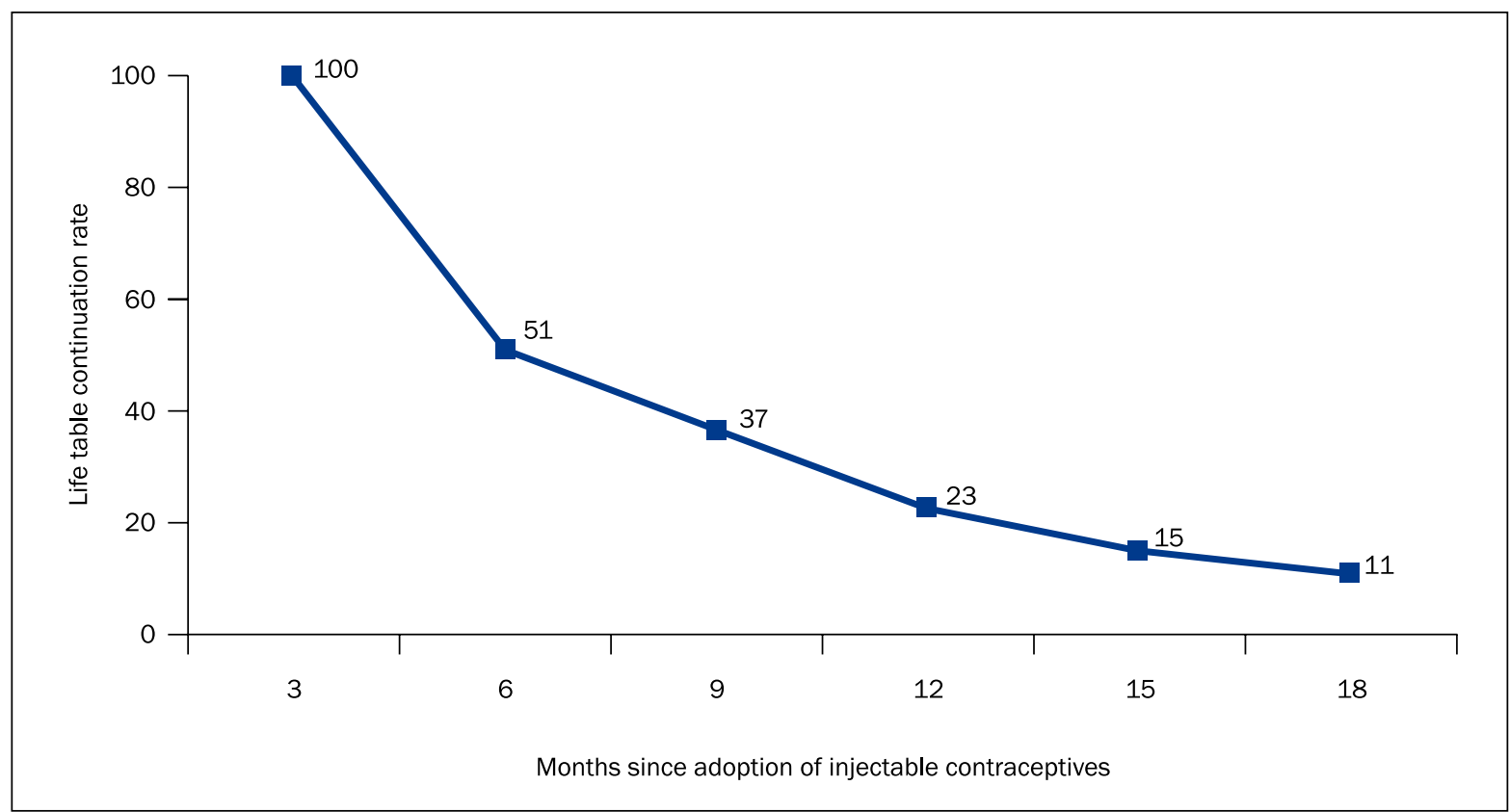

Note: Eleven women who returned for a subsequent dose of injectable contraceptives three or more months after the scheduled appointment for re-injection, have been treated as having discontinued the method.

\section{Use failure}

In one case, the woman reported that she was late for her re-injection and had become pregnant during this period, thus giving a typical use failure rate of 0.3 percent.

\section{Reasons for discontinuation}

The 329 women who had discontinued the use of injectable contraceptives any time up to the time of the interview were probed about their reasons for discontinuation. Findings, presented in Table 3.8, suggest that, as observed in previous studies, the reasons for discontinuation centred largely around the side effects experienced. Some 65 percent of all those who had discontinued the method cited a health-related reason for doing so. The leading side effect, again as noted in other studies, was menstrual disturbances. In total, more than half of all users (53\%) reported that they had discontinued using injectable contraceptives because of irregular menstruation, heavy bleeding or amenorrhoea associated with method use. In addition, some 37 percent reported such other side effects as vaginal discharge, swelling of hands and feet, itching, pain and weight gain. The second most often cited cluster of reasons for discontinuation was method-related: some 20 percent reported that they had planned to switch to another method, did not like the method, had doubts about it, needed a break from it or that the method was not convenient to use. A third group of reasons were access-related, centring around difficulties in accessing supplies: 16 percent cited these reasons, mostly concerning difficulties in reaching the facility to obtain subsequent doses of injectable contraceptives. Finally, some 10 percent of those who had discontinued cited fertility-related reasons: in order to become pregnant or because they 
Table 3.8

Factors underlying discontinuation: Percentage of women who discontinued use of injectable contraceptives by dose after which the method was discontinued and reason(s) for discontinuation

\begin{tabular}{|c|c|c|c|c|c|}
\hline \multirow[b]{2}{*}{ Reasons for discontinuation } & \multirow{2}{*}{$\begin{array}{l}\text { All women } \\
\text { who had } \\
\text { discontinued } \\
\text { injectable } \\
\text { contraceptive } \\
\text { use }\end{array}$} & \multicolumn{4}{|c|}{$\begin{array}{l}\text { Women who discontinued injectable } \\
\text { contraceptive use by dose after which the } \\
\text { method was discontinued }\end{array}$} \\
\hline & & $\begin{array}{c}1^{\text {st }} \\
\text { dose }\end{array}$ & $\begin{array}{c}2^{\text {nd }} \\
\text { dose }\end{array}$ & $\begin{array}{l}3^{\text {rd }} \\
\text { dose }\end{array}$ & $\begin{array}{l}4^{\text {th }}-8^{\text {th }} \\
\text { doses }\end{array}$ \\
\hline Health-related reasons & 65.0 & 70.5 & 59.3 & 62.7 & 51.2 \\
\hline a. Menstrual disturbances & 52.6 & 61.7 & 35.2 & 49.0 & 39.0 \\
\hline Irregular menstruation & 18.5 & 21.3 & 16.7 & 13.7 & 14.6 \\
\hline Heavy bleeding & 18.8 & 25.7 & 11.1 & 9.8 & 9.8 \\
\hline Amenorrhoea & 24.3 & 25.7 & 13.0 & 35.3 & 19.5 \\
\hline b. Other & 37.4 & 38.8 & 42.6 & 33.3 & 29.3 \\
\hline $\begin{array}{l}\text { Negative effect on health (includes infection, white } \\
\text { discharge, swelling in hands and feet, itching, } \\
\text { abdominal pain, weight gain) }\end{array}$ & 37.4 & 38.8 & 42.6 & 33.3 & 29.3 \\
\hline Method-related reasons & 20.4 & 19.7 & 14.8 & 17.6 & 34.1 \\
\hline Planned to switch to another method & 9.4 & 9.3 & 3.7 & 5.9 & 22.0 \\
\hline Did not like the method & 3.6 & 4.4 & 3.7 & 0.0 & 4.9 \\
\hline $\begin{array}{l}\text { Not convinced/Had doubts about injectable } \\
\text { contraceptives }\end{array}$ & 8.2 & 8.2 & 7.4 & 11.8 & 4.9 \\
\hline Needed a break from injectable contraceptive use & 1.2 & 0.0 & 0.0 & 2.0 & 7.3 \\
\hline Method not convenient to use & 0.3 & 0.0 & 1.9 & 0.0 & 0.0 \\
\hline Access-related reasons & 16.1 & 13.7 & 27.8 & 15.7 & 12.2 \\
\hline Difficulty in reaching the facility & 13.4 & 12.0 & 20.4 & 13.7 & 9.8 \\
\hline High cost of injectables & 1.8 & 1.6 & 3.7 & 0.0 & 2.4 \\
\hline Health care provider not easily accessible & 0.6 & 0.0 & 1.9 & 2.0 & 0.0 \\
\hline $\begin{array}{l}\text { Injectable contraceptives were not available at the } \\
\text { clinic }\end{array}$ & 0.9 & 0.5 & 3.7 & 0.0 & 0.0 \\
\hline Fertility-related reasons & 10.3 & 10.4 & 7.4 & 13.7 & 9.8 \\
\hline Planning a pregnancy & 4.9 & 3.8 & 3.7 & 5.9 & 9.8 \\
\hline Not having sex/Infrequent sex/Husband away & 5.2 & 6.6 & 1.9 & 7.8 & 0.0 \\
\hline Menopausal/Had a hysterectomy & 0.6 & 0.0 & 1.9 & 2.0 & 0.0 \\
\hline Use failure & 0.3 & 0.5 & 0.0 & 0.0 & 0.0 \\
\hline Number of discontinuers & 329 & 183 & 54 & 51 & 41 \\
\hline
\end{tabular}

Note: Multiple responses possible. 
were infecund or not engaging in sexual relations regularly. As noted above, one woman reported use failure as a reason for discontinuation.

What is notable is that irrespective of the duration of use of injectable contraceptives, menstrual disturbances remain the leading reason that women attributed to discontinuation of the method. At the same time, there is an inverse association between duration of use and reported discontinuation attributed to menstrual disturbances: from 62 percent after the first dose to 39 percent after the fourth or subsequent dose. Other reasons for discontinuation did not vary as widely. For example, other side effects were reported to have influenced discontinuation for 39 percent of users who discontinued after the first dose, as compared to 29 percent of those who discontinued after the fourth or subsequent dose. Other reasons were typically cited by fewer women and do not show a consistent pattern over the period of use. For example, method-related reasons were cited by 15-20 percent among those who discontinued after the first, second and third doses, respectively, but increased to 34 percent thereafter. Fertilityrelated reasons ranged from 14 percent to seven percent, while access-related reasons increased from 14 percent to 28 percent among those who discontinued the method after the first and second doses, and fell to 12 percent among those who did so after the fourth or subsequent dose.

Figure 3.2 shows life-table continuation rates among women who had adopted injectable contraceptives, by side effects experienced: notably, any side effect, menstrual disturbances without any other side effect, and both menstrual disturbances and some other side effect (small numbers prevented

Figure 3.2 Life table continuation rates of injectable contraceptives at the completion of each tri-monthly dose by side effects experienced

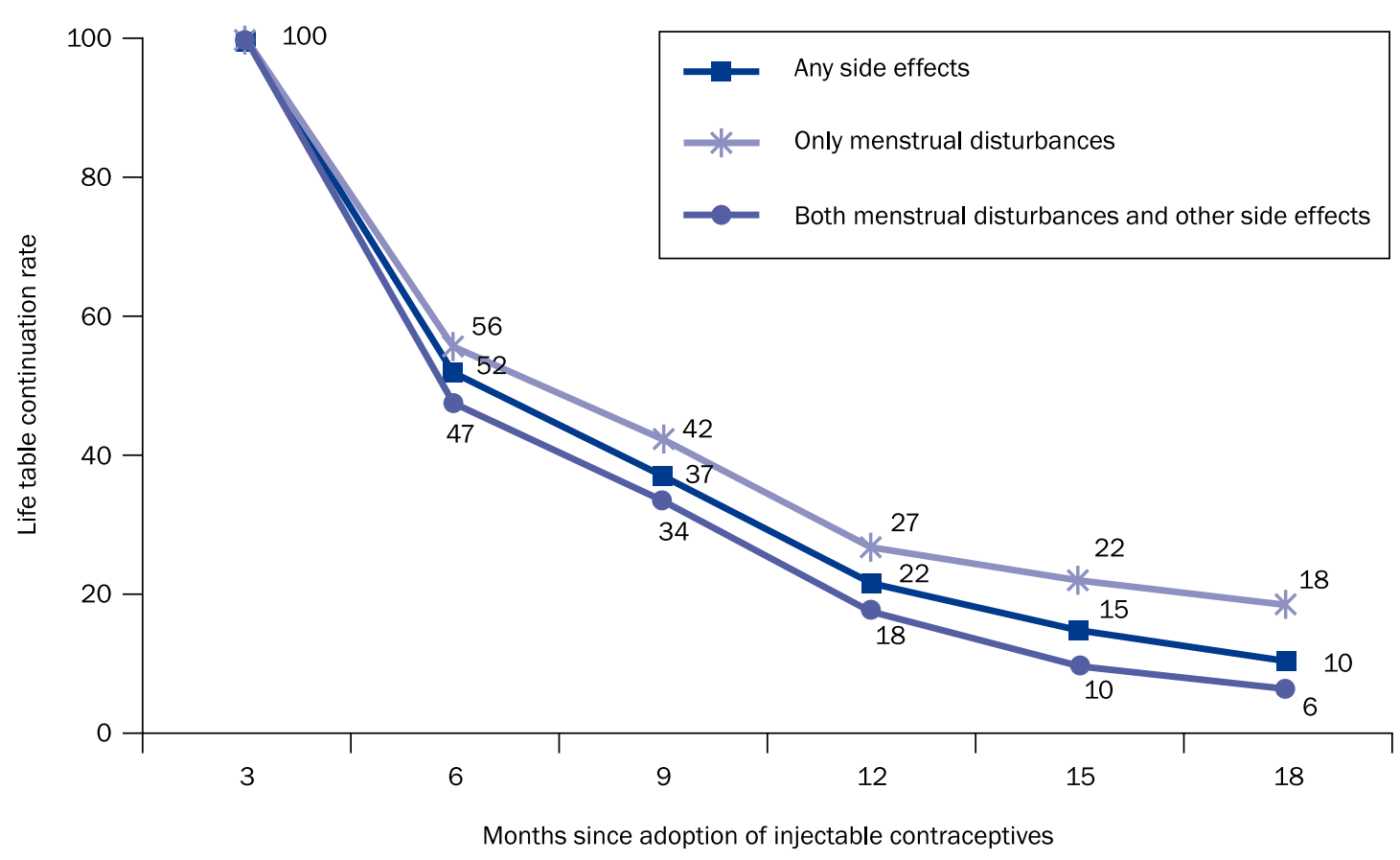


us from conducting the same exercise among those who experienced only other side effects). Continuation rates were largely similar up to six months of method use. Thereafter, differences emerged. Continuation rates were somewhat higher among those who experienced only menstrual disturbances than among those who experienced both menstrual disturbances and other side effects. For example, at nine months, 42 percent of those experiencing only menstrual disturbances had continued using the method compared to 34 percent of those experiencing both menstrual disturbances and other side effects; corresponding percentages were 27 percent and 18 percent, respectively, at month 12; 22 percent and 10 percent, respectively, at month 15; and 18 percent and 6 percent, respectively, at month 18 .

\section{Method switching}

A large proportion of women who had discontinued the use of injectable contraceptives switched to a different method, as evident from Table 3.9. Almost one-third $(31 \%)$ of discontinuers had switched directly to a terminal $(5 \%)$ or other non-terminal (26\%) method, and another 29 percent had discontinued contraceptive use entirely for more than one month, but adopted a terminal $(7 \%)$ or

\section{Table 3.9}

Of women who discontinued use of injectable contraceptives, percentages who had switched methods immediately and after a break of one or more months, by method adopted

\begin{tabular}{|c|c|}
\hline Contraceptive status of discontinuers & $\begin{array}{l}\text { Women who discontinued } \\
\text { injectable contraceptive use }\end{array}$ \\
\hline Discontinued and did not use any contraception & 40.4 \\
\hline Discontinued and switched immediately (within a month) to & 30.7 \\
\hline Oral contraceptive pills & 8.2 \\
\hline Intrauterine contraceptive device & 1.8 \\
\hline Condom & 11.9 \\
\hline Female sterilisation & 4.9 \\
\hline Periodic abstinence & 3.0 \\
\hline Withdrawal & 0.9 \\
\hline Discontinued and switched later (between one and three months) to & 28.9 \\
\hline Injectable contraceptives & 3.3 \\
\hline Oral contraceptive pills & 7.0 \\
\hline Intrauterine contraceptive device & 1.2 \\
\hline Condom & 6.4 \\
\hline Female sterilisation & 7.0 \\
\hline Periodic abstinence & 3.3 \\
\hline Withdrawal & 0.6 \\
\hline Number of discontinuers & 329 \\
\hline
\end{tabular}


other non-terminal (22\%) method thereafter. Indeed, three percent of discontinuers opted to return to the method after a one- to three-month break. Overall, however, 40 percent of women who had discontinued method use had not adopted another method until the date of the interview; as many as 10 percent had deliberately discontinued method use in order to become pregnant, because they were no longer at risk of pregnancy, or because they were not having regular relations with their husband.

Given the above profile of method switching, we explored all-method continuation rates (Figure 3.3). In view of the fact that many women switched from injectable contraceptives to another method without a break, the all-method continuation rate is considerably higher than the continuation rate of injectable contraceptives. For example, compared to a six-month continuation rate of 51 percent for injectable contraceptive use, the all-method continuation rate was 65 percent; corresponding percentages at 12 months were 23 percent and 45 percent, respectively. We also calculated an allmethod continuation rate that also includes women who discontinued injectable contraceptive use for a period of one to three months and then switched to another method (without becoming pregnant during these months); with this definition, the all-method continuation rates were 71 percent and 53 percent at six and 12 months, respectively.

\section{Acceptability of injectable contraceptives}

In order to assess the perceptions of injectable contraceptive users about the method, we asked them to list the positive and negative features of the method. As seen in Table 3.10, about three quarters of all women identified at least one positive feature. Large proportions of women reported, among its

Figure 3.3 Life table all-method contraceptive continuation rates among women who had adopted injectable contraceptives

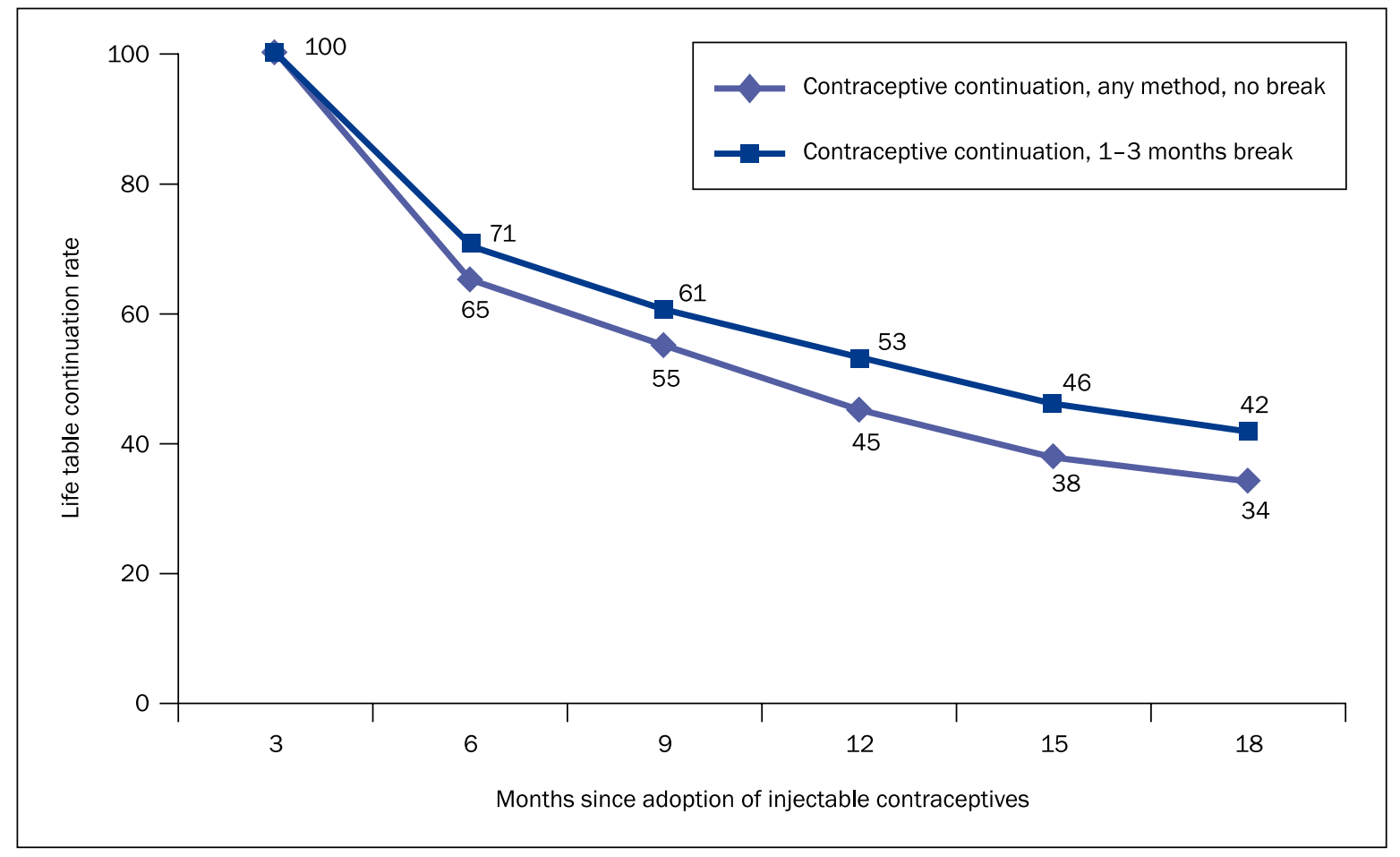


Table 3.10

Perceived features of injectable contraceptives among all women by duration of injectable contraceptive use

\begin{tabular}{|c|c|c|c|}
\hline $\begin{array}{l}\text { Perceived features of injectable } \\
\text { contraceptives }\end{array}$ & All women & $\begin{array}{l}\text { Women who } \\
\text { discontinued } \\
\text { injectable } \\
\text { contraceptive use } \\
\text { within } 12 \text { months } \\
\text { (three or fewer doses) } \\
\text { (\%) }\end{array}$ & $\begin{array}{c}\text { Women who } \\
\text { continued injectable } \\
\text { contraceptive use for } \\
12 \text { or more months } \\
\text { (at least four doses) } \\
(\%)\end{array}$ \\
\hline \multicolumn{4}{|l|}{ Positive features } \\
\hline Safety & 18.9 & 16.0 & $28.7^{* * *}$ \\
\hline $\begin{array}{l}\text { Enables women to effectively control } \\
\text { their fertility }\end{array}$ & 38.1 & 32.6 & $56.3^{* * *}$ \\
\hline $\begin{array}{l}\text { Long-acting, does not require a daily } \\
\text { routine }\end{array}$ & 34.9 & 31.3 & $47.1^{* * *}$ \\
\hline Easy to use & 23.7 & 18.8 & $40.2^{* * *}$ \\
\hline Reversible & 1.3 & 0.7 & $3.5^{* *}$ \\
\hline Can be used confidentially & 5.9 & 6.6 & 3.5 \\
\hline At least one positive feature & 75.2 & 70.1 & $91.9^{* * *}$ \\
\hline \multicolumn{4}{|l|}{ Negative features $^{a}$} \\
\hline Heavy bleeding & 17.6 & 20.8 & $6.9^{* * *}$ \\
\hline Spotting between menstrual periods & 4.0 & 3.8 & 4.6 \\
\hline Irregular periods & 20.8 & 22.6 & $14.9^{*}$ \\
\hline Amenorrhoea & 33.3 & 34.7 & 28.7 \\
\hline Backache & 6.7 & 6.6 & 6.9 \\
\hline Weakness & 23.2 & 25.4 & $16.1^{*}$ \\
\hline Weight gain & 12.5 & 10.4 & $19.5^{* *}$ \\
\hline Weight loss & 1.3 & 1.7 & 0.0 \\
\hline Foul-smelling vaginal discharge & 1.6 & 1.4 & 2.3 \\
\hline Inconvenient to use & 0.8 & 0.7 & 1.2 \\
\hline Cost & 0.8 & 1.0 & 0.0 \\
\hline Difficult to obtain repeat doses & 2.1 & 2.8 & 0.0 \\
\hline Stomach pain/heaviness & 2.1 & 1.4 & $4.6^{*}$ \\
\hline $\begin{array}{l}\text { Body } / \mathrm{leg} / \mathrm{knee} / \mathrm{breast} \text { pain and } \\
\text { breathing problems }\end{array}$ & 3.2 & 3.5 & 2.3 \\
\hline Itchiness & 0.5 & 0.7 & 0.0 \\
\hline At least one negative feature & 72.8 & 77.8 & $56.3^{* * *}$ \\
\hline Number of women & 375 & 288 & 87 \\
\hline
\end{tabular}

Note: Multiple responses possible; ${ }^{a} 0.3$ percent reported other reasons, not included in the table; ${ }^{*} p<=0.10, \stackrel{* *}{p}<<=0.05$, ${ }^{* * *} p<=0.01$. 
positive features, that it enabled women to control their fertility (38\%), that it was long-acting and does not require a daily routine $(35 \%)$, that it is easy to use $(24 \%)$ and that it is safe $(19 \%)$. Although many women identified the positive features of injectable contraceptives, almost as many women (73\%) identified at least one negative feature of injectable contraceptives. Among its negative features, as expected, were the menstrual disturbances it causes: 33 percent reported amenorrhoea, 21 percent reported irregular periods and 18 percent reported heavy bleeding as its worst feature. Other negative aspects included weakness, reported by almost one in four women (23\%) and weight gain, reported by 13 percent of the women.

As expected, women who had discontinued the method before completing 12 months of use (three doses or fewer) were more likely than those who had continued using the method for 12 months or more (at least four doses) to report negative features. For example, 30 percent of the former group, compared to eight percent of the latter group could not identify a single positive feature of injectable contraceptives; conversely, while 22 percent of those who had discontinued the method before completing 12 months of use reported that the method did not have any negative features, as many as 44 percent of those who had continued for at least 12 months so reported. Women who continued using the method for at least 12 months were significantly more likely to report such positive features as its safety and effectiveness, and its long-acting nature and ease of use than were those who discontinued before completing 12 months of use. Conversely, those who discontinued before completing 12 months of use were significantly more likely than those who had continued using it for at least 12 months to report such negative features as heavy bleeding, irregular periods and weakness. What is notable is that large and similar proportions of both groups reported amenorrhoea as a negative feature of injectable contraceptives (35\% and 29\%, respectively), and weight gain was significantly more likely to be reported by those who had continued using the method for at least 12 months than those who had used it for shorter periods of time (20\% versus $10 \%)$.

Additionally, we asked injectable contraceptive users who had also used the IUCD and oral contraceptive pills, respectively, about their preferred method and the reason(s) for such preference (not shown in table). Among the 39 injectable contraceptive users who had also used an IUCD either before adopting or after discontinuing injectable contraceptives, 72 percent (28 women) said that they preferred injectable contraceptives. Leading reasons for this preference included that it was safer (57\%) and easier to use (57\%). Eleven injectable contraceptive users, who expressed a preference for the IUCD, also said that the IUCD was safer (6) and easier (1) to use; other reasons included the fact that it is longer-acting (3) and reversible (3).

Among the 92 injectable contraceptive users who had also used oral contraceptives at some point in their contraceptive careers, 53 percent reported that they preferred injectable contraceptives because they are long-acting, do not require a daily routine (78\%) and were perceived to be safer (29\%). Of the 43 women who preferred oral contraceptives, reasons for this preference included the perception that oral contraceptives are safer (63\%) and easier (42\%) to use, do not cause amenorrhoea (19\%), are more effective $(9 \%)$, are reversible $(9 \%)$, and allow women to control their own fertility confidentially $(16 \%)$.

\section{Factors influencing injectable contraceptive continuation}

Multivariate analysis was conducted to explore factors, both socio-demographic and use-related, 


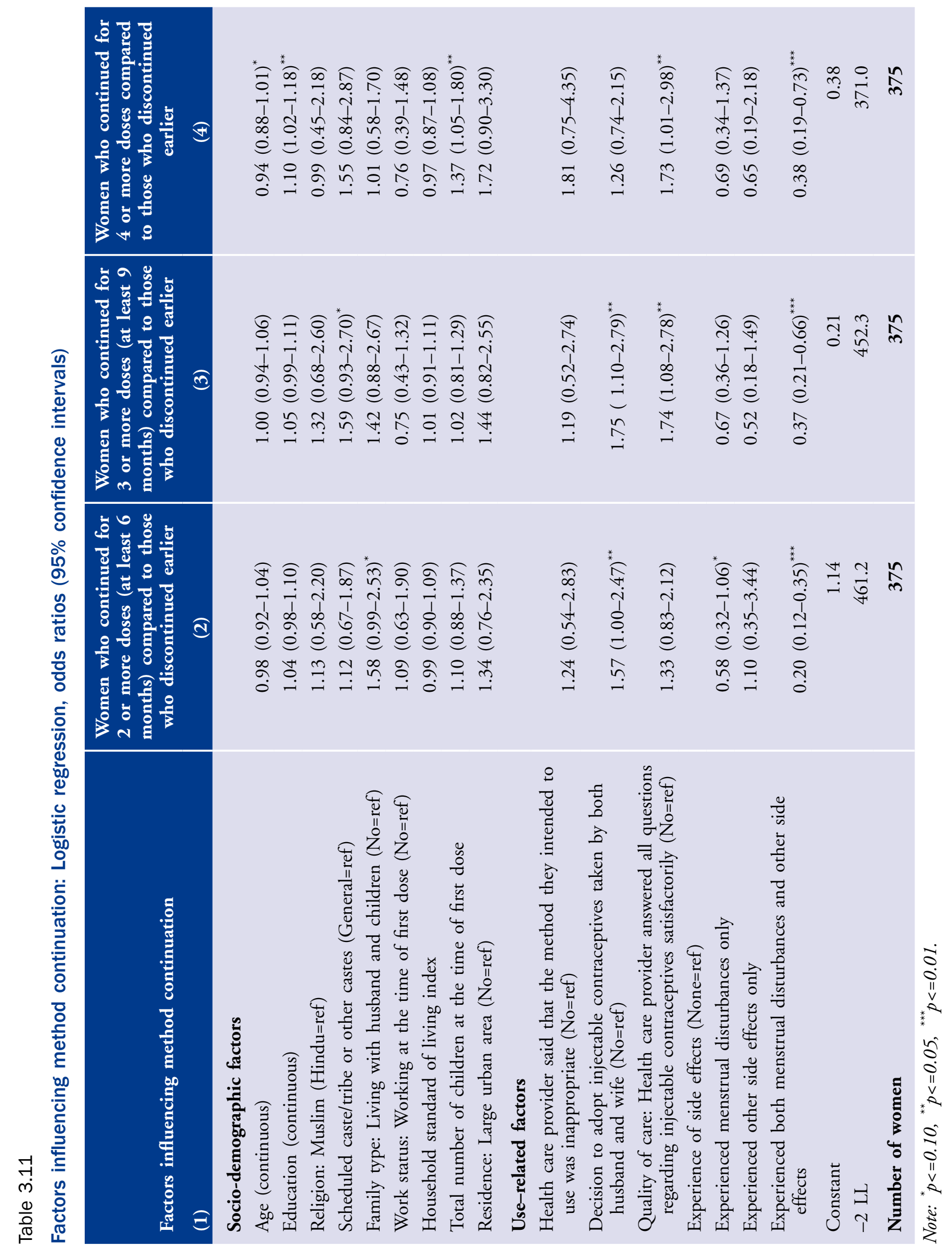


influencing the continuation of injectable contraceptive use. Findings, presented in Table 3.11, compare women who discontinued use of injectable contraceptives after the first dose with those who continued for two or more doses (Column 2), those who discontinued use of injectable contraceptives after the first or second dose with those who continued for three or more doses (Column 3), and those who discontinued use of injectable contraceptives after one to three doses with those who continued for four or more doses (Column 4).

Findings suggest that continuation was associated with a number of socio-demographic and userelated factors. As far as socio-demographic factors are concerned, for example, findings show that the odds that a woman had continued to use injectable contraceptives for at least six or nine months were unrelated with most socio-demographic variables. In contrast, the odds that a woman had continued to use injectable contraceptives for at least 12 months or four doses were greater among younger and better educated women, and those with larger numbers of children at the time of adopting injectable contraceptives as compared to other women.

Among use-related factors, the odds that a woman had continued to use injectable contraceptives for at least 6 months were greater among those who reported that the decision to use injectable contraceptives was made by both the woman and her husband, and were much lower among women who experienced menstrual disturbances only or both menstrual disturbances and other side effects compared to other women. Notably, continuation was not affected by the quality of care that is, whether or not the health care provider had answered all their questions satisfactorily. In contrast, the odds that a woman had continued to use injectable contraceptives for nine or more months were greater, as in the earlier case, among women who had reported joint decision-making and lower among those who experienced menstrual and other side effects; the odds were also greater among those who reported good quality of care as compared with other women. This general picture was evident also among women who had continued to use injectable contraceptives for 12 or more months compared to other women, except that joint decision-making was no longer significant in influencing method continuation.

\section{Summary}

Findings suggest that women obtained information about injectable contraception largely from health care providers, but also from family and friends. Irrespective of the source of information, about two-thirds of women who had adopted injectable contraception had made the decision to do so themselves, either on their own or together with their husband.

Injectable contraceptive related counselling was somewhat incomplete. While almost all the women had been informed about the need for three-monthly re-injections and their cost, and most had been informed about how the method works and the fact that it is a non-terminal method, fewer than half had been counselled about possible side effects, what to do if side effects were encountered, and the need to return to the service provider or facility in case of doubts about the method or if any side effects were experienced.

As other studies have observed, more than four in five women had experienced at least one side effect, largely menstrual disturbances or backache, weakness and weight gain. However, among women who had continued using injectable contraceptives for three or more doses, a comparison of side effects experienced by women between doses suggested that while the 
experience of menstrual disturbances, and notably amenorrhoea, declined marginally between doses, heavy bleeding fell significantly between the first and second doses. Experience of other side effects, in contrast, and notably weight gain, increased in the period between the first and second doses, and levelled off thereafter, while the experience of weakness and back pain increased more modestly between the first and second doses, and also levelled off thereafter. In all, about three-fifths of all women who experienced a side effect had complained about it to a health care provider and about one half noted that the side effect had affected their ability to perform their household responsibilities. Indeed, women who had experienced three or more side effects were more likely than other women to so report; women who had experienced menstrual disturbances were, on average, less likely to have complained and less likely to have reported that the side effect had affected their ability to perform their household responsibilities than were those who had experienced other side effects.

Life table continuation rates suggest that many women discontinued using injectable contraceptives after the first injection, and by 12 months, just 23 percent were continuing to use the method. Reasons for discontinuation centred largely around the side effects experienced, with two-thirds of all those who had discontinued injectable contraceptive use citing a health-related factor, largely menstrual disturbances, as the reason. Many fewer cited method-related reasons (that they planned to switch to another method, did not like the method, had doubts about it, needed a break from it, or that it was inconvenient to use), reasons related to difficulties in accessing supplies, and fertility-related reasons (that they wanted to become pregnant, were infecund or did not engage in sexual relations regularly). That side effects were a central reason for discontinuing injectable contraceptive use was evident from findings suggesting that life table continuation rates were considerably lower among women who experienced both menstrual disturbances and other side effects than among those who experienced just menstrual disturbances.

Following discontinuation of injectable contraceptive use, about three in ten women switched immediately to another contraceptive method; a similar proportion switched to another method (including those who switched back to injectable contraceptives) after a gap of one to three months, and about two in five women did not adopt another method even after a three month gap. All-method continuation rates suggest that by 12 months of the initial adoption of injectable contraceptives, as many as 45 percent continued to be protected by one or other contraceptive method. All-method continuation rates that include those who had discontinued contraception for a period of one to three months (but had not become pregnant) before switching to another method, suggest an all-method continuation rate of 53 percent at 12 months.

Overall, women were divided about the acceptability of injectable contraceptives. As many as one quarter of all women could not identify a single positive feature, and a slightly larger proportion could not identify a single negative feature of injectable contraceptives. Key positive features included that it enables women to control their fertility, that it is long-acting and does not require a daily routine, that it is easy to use and that it is safe. Key negative features, as expected, were the menstrual disturbances and other health-related side effects caused by injectable contraceptives. Women who had discontinued the method before completing 12 months of use (three doses or fewer) were more likely than those who had continued using the 
method for 12 months or more (at least four doses) to report its negative features and correspondingly, were significantly more likely to report such positive features as its safety and effectiveness, its longacting nature and ease of use than were those who had discontinued before completing 12 months of use. Over one half of women who had used injectable contraceptives as well as the IUCD or oral contraceptive pills (prior to adoption of injectable contraceptives or post discontinuation) reported that they preferred to use injectable contraceptives. Leading reasons for this preference included its perceived safety, ease of use, long-acting nature and, in comparison to oral contraceptive pills, that it did not require a daily routine.

Continuation of injectable contraceptive use, as assessed by multivariate analysis, was largely associated with a number of socio-demographic and use-related factors. The odds that a woman had continued to use injectable contraceptives for at least 12 months, for example, were greater among younger and better educated women, and those with larger numbers of children at the time of taking the first dose of injectable contraceptives as compared to other women; the odds were greater among those who had received good quality of care and lower among those who had experienced menstrual disturbances along with other side effects. Some notable differences appeared to mark discontinuation earlier than 12 months. For example, joint decisionmaking with the husband was an important correlate of continuation beyond three and six months but did not remain significant thereafter; and quality of care was unrelated with continuation beyond three months but became significant thereafter. 


\section{Perspectives on injectable contraceptives among women seeking to adopt contraception}

A secondary objective of this study was to assess the extent to which new method adopters opted for injectable contraceptives and their motivations for adopting the method selected. A survey, comprising exit interviews, was conducted among women seeking to adopt a contraceptive method from the facilities from which our sample of women who had earlier adopted injectable contraceptives was drawn. Interviewers spent two to three days in each facility and interviewed all consenting women who sought to adopt contraceptive services on those days. The interviews aimed to explore two main issues: the extent to which pre-adoption counselling had included injectable contraceptives among the range of contraceptives described to the woman and the kind of information about injectable contraceptives provided; and the method finally adopted and reasons for adopting or not adopting injectable contraceptives. A total of 117 women seeking to adopt contraception in study facilities were interviewed.

\section{Pre-adoption counselling}

Descriptions of pre-adoption counselling suggest that injectable contraceptives were included among the basket of contraceptives offered to just one quarter $(24 \%)$ of women seeking contraception, as seen in Table 4.1. Of the 28 women who reported that the health care provider had indeed discussed injectable contraceptives with them, the kinds of issues addressed resemble those described by women who had adopted injectable contraceptives in March to September, 2010. For example, all women were informed that they would have to return to the facility every three months to repeat the dose of injectable contraceptives and 82 percent were told the advantages of using the method. However, considerably fewer reported that the health care

Table 4.1

Percentage of women seeking to adopt contraception by pre-adoption counselling received

Content of pre-adoption counselling

Health care provider talked about injectable contraceptives

Among those to whom the health care provider talked about injectable contraceptives

Told about the advantages of using injectable contraceptives

Told about the three month follow-up visit for repeating injections

Told about the cost of each injection

Told about the possible side effects of injectable contraceptives
Women seeking to adopt contraception

$$
23.9
$$

$(\mathrm{N}=117)$

$\mathrm{N}=\mathbf{2 8}$

82.1

100.0

57.1

46.4 
provider had informed them about the cost of each dose of injectable contraceptives (57\%), and fewer than half $(46 \%)$ reported receiving information about the possible side effects of the method.

\section{Method adopted}

The large majority of women reported that they had decided the method they wished to adopt prior to attending the facility. As evident from Table 4.2, the majority (62\%) had planned to adopt and had indeed adopted female sterilisation (60\%). Others had opted for non-terminal methods: 15 percent for the IUCD, five percent for oral contraceptives and four percent for injectable contraceptives. In short, one-sixth of all women who had a specific non-terminal method in mind had planned to adopt injectable contraceptives and one-fifth (10 of 47) of those who adopted a non-terminal method had opted for injectable contraceptives. We acknowledge that this large proportion opting for injectable contraceptives may reflect the fact that the NGO facilities in which the study was located were wellknown for offering injectable contraceptives; and hence their clientele may not be representative of all women seeking to adopt contraception more generally. Aside from those who had a method in mind when they visited the facility, 11 percent reported that they had been undecided about which method to adopt when they visited the facility.

Most women, 95 of the 104 who had a particular method in mind (91\%), had adopted the method they had intended to adopt. Of the 13 women who were undecided about which method to adopt, two opted for tubal ligation, seven for oral contraceptives, two for condoms, and two for injectable contraceptives. Of the eight women who had planned to adopt a particular method and adopted a different method, five, two and one, respectively, had intended to adopt tubal ligation, the IUCD and oral contraceptive pills, but none of

Table 4.2

Percentage of women seeking to adopt contraception by contraceptive method they intended to adopt and the method adopted

\begin{tabular}{l|c|c|}
\multirow{2}{*}{ Method } & \multicolumn{2}{|c|}{ All women } \\
\cline { 2 - 3 } & $\begin{array}{c}\text { Method the woman } \\
\text { intended to adopt }\end{array}$ & $\begin{array}{c}\text { Method adopted by } \\
\text { the woman }\end{array}$ \\
\hline Male sterilisation & 0.9 & 0.9 \\
Female sterilisation & 62.4 & 59.8 \\
Iintrauterine contraceptive device & 14.5 & $12.8^{*}$ \\
Oral contraceptive pills & 5.1 & 14.5 \\
Condom & 1.7 & 3.4 \\
Injectable contraceptives & 4.3 & 8.5 \\
No method planned & 11.1 & $* *$ \\
Number of women & $\mathbf{1 1 7}$ & $\mathbf{1 1 7}$
\end{tabular}

Note: "Includes one woman who was provided the emergency contraceptive pill and asked to return in two weeks to have the IUCD inserted; " Includes 13 women who adopted tubal ligation(2), oral contraceptive pills(7), condoms(2) and injectable contraceptives(2). 
these women obtained the method she had originally decided upon; instead, the methods adopted were oral contraceptives (five women) and injectable contraceptives (three women). Most women who had not adopted their intended method reported that the health care provider had dissuaded them from adopting that method, indicating that it would not be appropriate in their situation (further details were not probed).

In short, a comparison of the method women intended to adopt and the method actually adopted suggests a shift away from terminal to non-terminal methods, and towards such non-terminal methods as oral and injectable contraceptives.

Decision-making with regard to the method finally adopted suggests that 80 percent of all women had made the final decision about which method to adopt on their own or together with their husband, mother-in-law or health care provider. As many as 62 percent reported that they and their husbands, they alone (18\%) and their husband alone (13\%) had made the final decision. Some 21 percent reported the involvement of a health care provider and nine percent of their mother-in-law. It is notable that one-fifth of all women were excluded from the final decision on which method to adopt (not shown in table).

\section{Method preferences}

Exit interviews explored the reasons that the 107 women who had adopted methods aside from injectable contraceptives gave for not adopting this method. As shown in Table 4.3, the large majorityas many as two-thirds-reported lack of awareness of injectable contraceptives. A second leading factor dissuading women from adopting injectable contraceptives was the fear of side effects (18\%). Other concerns included difficulty in accessing the facility for repeat doses (9\%), high cost of repeat

Table 4.3

\section{Reasons for non-adoption of injectable contraceptives}

\begin{tabular}{|c|c|c|c|}
\hline $\begin{array}{l}\text { Reasons given for non-adoption of } \\
\text { injectable contraceptives }\end{array}$ & $\begin{array}{l}\text { Women who adopted } \\
\text { all methods other } \\
\text { than injectable } \\
\text { contraceptives } \\
(\%)\end{array}$ & $\begin{array}{l}\text { Number of women } \\
\text { who adopted } \\
\text { the IUCD } \\
\text { (n) }\end{array}$ & $\begin{array}{l}\text { Number of women } \\
\text { who adopted oral } \\
\text { contraceptives } \\
\text { (n) }\end{array}$ \\
\hline $\begin{array}{l}\text { Not aware of injectable } \\
\text { contraceptives }\end{array}$ & 65.4 & 8 & 8 \\
\hline $\begin{array}{l}\text { Fear of side effects of injectable } \\
\text { contraceptives }\end{array}$ & 17.8 & 4 & 3 \\
\hline $\begin{array}{l}\text { Difficulty in accessing the facility for } \\
\text { repeat doses }\end{array}$ & 9.3 & 2 & 2 \\
\hline $\begin{array}{l}\text { Husband disapproves of injectable } \\
\text { contraceptives }\end{array}$ & 7.5 & 1 & 1 \\
\hline Cost of repeat doses & 2.8 & 0 & 1 \\
\hline Preference for tubal ligation & 0.9 & 0 & 0 \\
\hline $\begin{array}{l}\text { Health care provider dissuaded } \\
\text { injectable contraceptive use }\end{array}$ & 3.7 & 1 & 2 \\
\hline Number of women & 107 & 14 & 17 \\
\hline
\end{tabular}

Note: Multiple responses possible. 
doses (3\%), husband's disapproval of the method (8\%) and preference for tubal ligation (1\%). In addition, four percent of women reported that the health care provider had dissuaded them from adopting injectable contraceptives.

A roughly similar picture emerges when we explore the reasons that women who adopted the IUCD and oral contraceptives gave for preferring these methods to injectable contraceptives. While numbers are small, it is clear that the potential side effects of injectable contraceptives are a significant deterrent. So too were difficulties associated with accessing the facility for repeat doses of injectable contraceptives, even compared to oral contraceptives which could be accessed from a number of outlets closer to the woman's home and did not require a return visit to the facility.

Women who had adopted injectable contraceptives highlighted a number of advantages of the method over oral contraceptive pills, for example. Of the 10 women who had adopted injectable contraceptives, five reported that a key advantage over oral contraceptives was that it is long-acting and does not require a daily routine; five also reported that it is "easier" to use; three reported that it offered women greater confidentiality; and two mentioned that it is a highly effective method. Not a single woman reported that the method had fewer side effects (not shown in table).

\section{Summary}

Exit interviews with women seeking to adopt contraception revealed that just nine percent of women seeking contraception and about one-fifth of those who opted for a non-terminal method at study facilities had adopted injectable contraceptives. Findings suggest a number of factors underlying the relatively limited adoption of this method. Many women were unaware of the method. Indeed, two-thirds of those who had adopted other methods reported that they were unaware of the availability of injectable contraceptives. As most women had adopted the method they had intended to adopt prior to visiting the facility on the day of the interview, this lack of general awareness is likely a key factor inhibiting the use of injectable contraceptives. At the same time, information was unlikely to be provided at the facility: few women, just one in four, were informed about the availability of injectable contraceptives during pre-adoption counselling by the health care provider.

Further insights come from women who had adopted methods other than injectable contraceptives. For example, fear of side effects was clearly a major factor inhibiting the adoption of injectable contraceptives. The cost of injectable contraceptive repeat doses was an inhibiting factor for a few women who adopted oral contraceptive pills and the IUCD. Moreover, the need to access the facility for repeat doses of injectable contraceptives was perceived as a serious disadvantage by many who regarded the IUCD, in comparision, as a method not requiring repeated follow-up and oral contraceptives, as one that could be purchased or obtained from facilities and outlets closer to home. 


\section{Perspectives of health care providers on injectable contraceptives}

The study also sought to obtain the perspectives of health care providers on a number of issues relating to the use of injectable contraceptives. Interviews addressed, for example, health care providers' own experience of providing injectable contraceptives: the number of clients to whom they had supplied injectable contraceptives, the type of counselling provided to users and potential users, and provider biases, if any, in terms of which type of client should be offered or should be denied injectable contraceptives. They were also probed about the experiences of their clients who had used injectable contraceptives, and specifically, their clients' prior awareness about the method, continuation, side effects experienced, follow-up and acceptability. Finally, they were asked for their opinion about the possible inclusion of injectable contraceptives in the national programme, and their recommendations, if any, about how the method should be rolled out.

As mentioned earlier, a total of 16 health care providers were interviewed, at least one from each participating NGO. All health care providers indicated that the facility in which they worked offered a range of contraceptive services, including both terminal methods and injectable contraceptives, and abortion services. A few also mentioned the provision of antenatal and postpartum services, services related to sexually transmitted infections and adolescent counselling.

\section{Health care provider perceptions about method preferences of clients}

Health care providers were asked to estimate the number of women to whom they had provided injectable contraceptives in the year and month preceding the interview. A range of responses were received, for example, from ' $20-40$ ' to 'about 1000 ' in the year preceding the interview, and from ' $2-3$ ' to '20-30' in the month preceding it. A few health care providers stated that large numbers of women sought tubal ligation:

Very few come for other contraceptives; the maximum number of clients come for sterilisation as it is a permanent method. They don't have much interest in temporary methods as they have many things (doubts) in their mind regarding the side effects of these methods. (Dr. B, age group 40-49)

Most women accept sterilisation. (Dr. D, age group 30-39)

Rural clients prefer a permanent method. Urban clients accept temporary methods; they use injectables and the Cu-T (IUCD) as temporary methods. (Dr. K, age group 40-49)

Other health care providers discussed the demand for non-terminal methods among women seeking contraception. Four health care providers said 
that the IUCD $(\mathrm{Cu}-\mathrm{T})$ was the most commonly desired non-terminal method among women seeking contraception in their facilities. Health care providers indicated:

Few clients use oral contraceptive pills. Mostly, they use the Cu-T as a temporary method.

(Dr. J, age group $50+$ )

Mostly, women accept IUCDs. (Dr. C, age group 50+)

(Most women opt for the) Cu-T. (Dr. A, age group $50+)$

Aside from sterilisation, most women accept the $\mathrm{Cu}$-T. (Dr. M, age group 40-49)

However, several health care providers noted women's interest in injectable contraceptives:

They use two methods, the Cu-T first, and next, they prefer injectables. (Dr. $\mathrm{H}$, age group 30-39)

Mostly, women accept oral contraceptives; there are some misconceptions about the Cu-T...

Nowadays, many women have been showing a preference for injectables. (Dr. N, age group 40-49)

Some women (are interested); (because) injectable contraceptives have few side effects; pills give problems like nausea, vomiting etc. On the other hand, if the husband doesn't wish to use Nirodh (condom) or doesn't use it properly, there are chances of the woman conceiving. Women feel assured that with injectable contraceptives, they will not conceive and that it has few side effects; also, after proper counselling, their misconceptions, such as concerns about weakness, are reduced.

(Dr. N, age group 40-49)
Women like to accept injectable contraceptives as the method is easy to use; in comparison, they don't like to accept the Cu-T because of the fear of infection and the insertion procedure.

(Dr. P, age group 50+)

\section{Health care provider perceptions about the advantages and disadvantages of injectable contraceptives}

Health care providers were mixed about their views on the appropriateness of injectable contraceptives as a viable method for their clientele. Almost all agreed that it is a safe and effective method,:

The first advantage (of injectable contraceptives) is their low failure rate; second, the method is good as there is no problem of taking it daily as in the case of pills, and third, privacy can be maintained. (Dr. G, age group 50+)

It is a good method but there are side effects.

(Dr. A, age group 50+)

Injectable contraceptives are a very good, effective and safe method, provided proper counselling is given regarding side effects...it is not required to be taken daily. Secondly, after a gap of three months, it is not absolutely necessary to take the next dose on a fixed date as its window period is also good. (Dr. L, age group 50+)

Injectable contraceptives are a confidential method; privacy is maintained and it has to be taken only once in three months. (Dr. P, age group 50+)

As a temporary method for one or two years, it is a good method. However, if it is to be used for a longer period, it is important to know its advantages and disadvantages. (Dr. K, age group 40-49) 
We prefer the Cu-T because if there is any problem or it doesn't suit the woman, we can remove it immediately, but if injectable contraceptives enter the body, we cannot do anything. Also, after discontinuing injectable contraceptives, the woman's menses doesn't return for six months to a year. (Dr. M, age group 40-49)

At the same time, health care providers acknowledged that the method is associated with many side effects and that these side effects made injectable contraceptives an unattractive option for women. In fact, every single health care provider noted that menstrual disturbances are a major side effect of injectable contraceptives. Indeed, several said that neither heavy bleeding nor amenorrhoea were acceptable side effects for women. Health care providers reported that many women who experience these side effects express the fear of having a serious disease and those who experience amenorrhoea fear that they are pregnant. Moreover, because of cultural practices that forbid menstruating women from entering the kitchen or praying, heavy bleeding or irregular menstruation affected their ability to perform these regular tasks:

It is a good method, but there are side effects....

When it suits the woman, she is happy and takes three to four doses. But then, if a problem occurs, she asks me, 'What kind of injection have you given me?' (Dr. A, age group 50+)

Not a very good method; it disturbs menstruation greatly. Women come here in tension as they have continuous bleeding or bleeding (menstrual period) has completely stopped. (Dr. B, age group 40-49)

It is a good method but it has many side effects like amenorrhoea. In such a situation, the client gets disturbed, thinking about why she does not menstruate; she is afraid that she may be suffering from some disease. (Dr. C, age group 50+)

Side effects are not acceptable; women feel disturbed if they experience amenorrhoea and worry whether or not they are pregnant again.

(Dr. E, age group 30-39)

Women who have bleeding-related problems, feel uneasy; otherwise, they are happy. Fifty percent discontinue the method because of amenorrhoea. (Dr. G, age group 50+)

I don't find any drawback as such, but if amenorrhoea occurs as a side effect, then it is a cause for concern. (Dr. N, age group 40-49)

Irregular bleeding is a very big problem with injectables. It is a problem in our context because when a woman is bleeding, she is unable to worship God and it disturbs her psychologically; so, women don't wish to accept the method. The second problem is that if a woman experiences irregular bleeding, we are unable to tell her when it will stop. Once injectables are used, the effect of the drug remains for three months, and we can't do anything about it. (Dr. O, age group 40-49)

A number of health care providers also stated that delayed resumption of menstruation and prolonged time to conception following discontinuation of injectable contraceptives was a disadvantage especially for women intending to have another pregnancy on discontinuation of the method. They argued that time to conception was far longer than that associated with the $\mathrm{Cu}-\mathrm{T}$ or oral contraceptives, and may not therefore be attractive to women seeking to space their births. For example:

After removing the $\mathrm{Cu}$-T, the woman can conceive easily whereas it takes some time to conceive after stopping injectables... Women know 
that after stopping injectables, it will take one year to conceive, so they stop after a few doses.

(Dr. H, age group 30-39)

Some women are not able to conceive for many days after they stop using injectable contraceptives.

(Dr. F, age group 40-49)

Sometimes, after stopping the injections, there is a delay in (the resumption of) menses for six months or a year. (Dr. A, age group 50+)

After stopping (discontinuing use), women are unable to conceive; they go into secondary infertility and have to undergo treatment for many days (for the resumption of menstruation).

(Dr. B, age group 40-49)

After discontinuing injectable contraceptives, the next pregnancy could be delayed; it is not so with other methods. The calcium level also goes down with the use of this method; this is not visible but it could cause a problem. (Dr. K, age group 40-49)

If a client is newly married and does not have even one child, we cannot give her injectables because sometimes fertility is delayed, whereas after discontinuing the oral contraceptive pill, pregnancy can happen soon. (Dr. L, age group 50+)

Finally, we note that although injectable contraceptives are recommended for use in the postpartum period and by lactating women (World Health Organization, 2010), this advantage was not specifically indicated by a single health care provider.

\section{Health care provider perceptions about factors dissuading women from adopting injectable contraceptives}

Several health care providers also highlighted the obstacles that dissuaded women from adopting injectable contraceptives, once fully informed. Leading obstacles included the inconvenience of returning to the facility every three months for reinjections, fear of side effects and cost. For example:

Everyone asks about injectables, but they want a one-time injection: if we tell them that they will have to come every three months, they are not willing (to adopt the method). (Dr. C, age group 50+)

They don't have much interest (in injectable contraceptives) as they have many doubts in their mind about side effects. (Dr. B, age group 40-49)

Mostly women prefer the Cu-T because once inserted, they can be tension-free; they just have to pay Rs 50 once, whereas for injectables they have to pay Rs 50 every three months.

(Dr. F, age group 40-49)

\section{Health care provider perceptions on the appropriateness of injectable contraceptives for different groups of women}

In the course of the in-depth interview, we made efforts to gauge the perspectives of health care providers about the appropriateness of injectable contraceptives for women in India, including whether health care providers would hesitate to offer injectable contraceptives to poor or poorly educated women.

While almost all health care providers were in agreement that injectable contraceptives are a safe and effective method, many acknowledged that it is not an appropriate method for all women. For example, several health care providers indicated that they would recommend the method to only certain categories of women based on the woman's age and fertility intentions; for example, they would offer 
it to women who do not want another child, or to older women, but would refrain from suggesting it to those who are newly married or to those who intend to have a child on discontinuation of the method.

If the woman is young or newly married, I don't recommend the Cu-T generally, but condoms or oral pills are fine. On the other hand, if the woman is older and her family is complete, we advise sterilisation. (Dr. E, age group 30-39)

If the client is newly married then we don't recommend the $\mathrm{Cu}-\mathrm{T}$ or injectable contraceptives as there are chances of infection with both these methods, and if infection does occur, the entire blame is placed either on the provider or on the method. (Dr. P, age group 50+)

If the client doesn't even have one child, I do not advise injectables. (Dr. J, age group 50+)

We mostly recommend the $\mathrm{Cu}-\mathrm{T}$ and injectables, but we prefer the $\mathrm{Cu}$-T for women who may want another child. (Dr. H, age group 30-39)

It is a good method, provided the woman's family is complete and she is above 35 years. (Dr. I, age group 30-39)

Age matters because at pre-menopausal ages, hormonal methods of contraception should be avoided. (Dr. O, age group 40-49)

A few health care providers described in detail the extent to which it was important to obtain the woman's full history as there were certain health conditions under which they would not recommend injectable contraceptives. For example:

Normally we do not advise injectables to a woman who has a bleeding-related problem, a cyst in the ovaries, a problem in the cervix or a cyst in the breast. So, we avoid giving injectables to such women. (Dr. G, age group 50+)
We have to assess her family background, her history, and do her physical screening. A particular method may not be suitable for certain clients, and even so, not for her entire reproductive life. If a woman comes after delivery, we prescribe the oral pill. We also need to see the age of her last child and which method she wishes to adopt. (Dr. L, age group 50+)

As regards offering injectable contraceptives to poor or poorly educated women, health care providers expressed divers views. A number of health care providers maintained that the extent to which the client was educated did not affect their decision to offer injectable contraceptives to them. For example, eight health care providers argued that socioeconomic factors were unimportant:

Her age, education or socioeconomic condition are not significant. (Dr. B, age group 40-49)

The client's socioeconomic condition is not significant. (Dr. D, age group 30-39)

The woman's socioeconomic condition is not significant. (Dr. G, age group 50+)

Education is not significant; if everything is explained nicely, even illiterate women are able to understand everything. (Dr. F, age group 40-49)

We provide information about each method, so education doesn't matter much-but it matters for natural methods like the safe period etc.

(Dr. H, age group 30-39)

Economic condition is not important; woman of all classes accept it (injectable contraceptives).

(Dr. I, age group 30-39)

Women, who are less educated or belong to a lower income group, accept it (injectable contraceptives); they have more faith in the doctor. (Dr. L, age group 50+) 
Economic conditions and educational

qualifications are of no significance as most clients coming from rural areas are illiterate or have studied up to a maximum of 6 th class only.

(Dr. M, age group 40-49)

At the same time, eight other health care health care providers affirmed that the poorly educated were less likely to comprehend the requirement of three-monthly injections and side effects associated with injectable contraceptives. Four of these health care providers suggested that they needed to spend more time explaining the method to poor or poorly educated women than others. For example:

If a woman is educated, she is able to understand (what she is told) about injectable contraceptives; we need to explain at length to village women.

(Dr. A, age group 50+)

We can explain everything regarding injectable contraceptives and other methods properly to educated women and they understand it. As compared to poorly educated women, educated women understand injectable contraception better. (Dr. C, age group 50+)

Educational qualifications matter because we have to explain more to a lesser educated client as only by doing so, we can follow up that client, which is very important. (Dr. O, age group 40-49)

Yes, educational qualification is significant... educated women understand the method and easily follow instructions about how to use the method. (Dr. P, age group 50+)

The remaining four health care providers of this group maintained that they would prefer to provide methods other than injectable contraceptives to poor or poorly educated women. Two reported that they would recommend injectable contraceptives to poorly educated women, but that the economic condition of the household did play a role in their decision to offer the method to the woman. For example:

Educational qualification is not significant... but socioeconomic condition matters because for some methods, the charges are too high and poor clients prefer to accept the cheapest method. (Dr. K, age group 40-49)

Economic status is important to some extent because if a woman needs to get a test done from a private facility, and her economic condition is not good, she will not be able to get her test done so easily. Injectables are not available in government facilities either, so we can give the method to the client only if she can afford it.

(Dr. N, age group 40-49)

Two others reported that they would recommend other methods to a poorly educated woman. For example:

Education is significant as educated women understand easily. They also understand the importance of follow up; to less educated women, we suggest the use of condoms. (Dr. E, age group 30-39)

Yes, educational qualification is significant.... I recommend methods to women according to their needs and educational status. (Dr. J, age group 50+)

\section{Injectable contraceptive related counselling offered by health care providers}

Efforts were made to understand the kind of counselling that health care providers offered potential clients and specifically, whether they involved the husband in the counselling session and if they permitted clients to make the final decision to adopt the method on her own. 
For the most part, health care providers indicated that counselling entailed the provision of such information as the mechanics of the method (how often it must be taken) and the kind of side effects that may occur. All health care providers indicated that they informed women about such side effects as amenorrhoea and heavy bleeding, and that the woman should return to the clinic if she experiences these side effects. However, although several health care providers had also discussed weight gain as a disadvantage, not a single health care provider mentioned that they would inform the client about this side effect.

We tell them after how many days it (the injection) is to be taken, about complications; we tell them everything. (Dr. A, age group 50+)

We inform them that this injection will function for three months only. We tell them about its side effects etc. (Dr. C, age group 50+)

We tell them that the monthly period may stop, bleeding may occur between periods, but there is nothing to worry about. (Dr. D, age group 30-39)

We provide information regarding side effects like bleeding, stopping of menses (amenorrhoea) and, at the same time, we also counsel them that there is nothing to worry about. (Dr. M, age group 40-49)

Several health care providers narrated, in detail, the importance of gathering the woman's complete history; they also highlighted to their clients the mechanics of the method and the potential menstrual disturbances that could arise. For example:

We counsel all women about injectable contraceptives but normally we do not advise injectables to a woman who has a bleedingrelated problem, a cyst in the ovaries, a problem in the cervix or a cyst in the breast. So, we avoid giving injectables to such women. First, I tell them that injectables are also a method of contraception which is to be taken after every three months and by taking which, the woman will not conceive. The second thing is that some women have a misconception that the injection is effective for three or five years; so, we clarify this too. Moreover, we also provide them information about irregular bleeding and amenorrhoea as side effects of the method; due to this, although some women refuse to take injectables, most accept the method. (Dr. G, age group 50+)

I take information about her menstrual history, menstruation-related problems and, at the same time, information about whether or not she has used any method previously and, if so, which method she has used and whether she had any problems using that method. If the woman is young or newly married, I don't recommend the Cu-T generally, but condoms or oral pills are fine. On the other hand, if the woman is older and her family is complete, we advise sterilisation. I tell them about the side effects of the injection such as amenorrhoea. If the woman is lactating, I tell her that her milk may be reduced. At the same time, I advise her to take an injectable dose after every three months. I also advise her to come to the clinic in case of any side effect and assure her that there is nothing to worry and the side effects, if any, can be cured with medicines.

(Dr. E, age group 30-39)

We need to know the client's complete history: whether she has any infection or any other problem. Most of our clients don't have such problems; hence, we don't discuss all these things with all our clients... First of all, I provide information regarding doses - that the injection is given after every three months, and by doing so, 
a child is not conceived, and that mostly, there is no problem (with its use). But it is important to also tell them about one side effect of injectable contraceptives and that is, secondary amenorrhoea. If we don't provide information about this side effect to the client, she will blame us if she happens to suffer from it later. (Dr. $\mathrm{H}$, age group 30-39)

We have to assess her family background, her history, and do her physical screening. A particular method may not be suitable for certain clients, and even so, not for her entire reproductive life. If a woman comes after delivery, we prescribe the oral pill. We also need to see the age of her last child and which method she wishes to adopt. (Dr. L, age group 50+)

Several health care providers discussed the importance of including the husband in the counselling session, although at least in one case, the health care provider maintained that even when husbands attended the counselling session, they rarely participated or asked questions during the discussion. Other health care providers highlighted the link between the husband's involvement and the quality of subsequent method use, and the perception that many women would not adopt a method without having discussed it with their husband. For example:

If both husband and wife are involved then acceptance is good; especially women who are educated want to take a decision after discussing with their husband. (Dr. K, age group 40-49)

Clients who belong to urban areas, generally come with their husband and he wishes to know which method is good for them, what are the advantages and disadvantages of the method, when to return and what they can do or not do. In particular, clients who are educated and whose husband is also educated, wish to have full information, but the husbands of clients who come from villages, don't get involved. (Dr. M, age group 40-49)

It is important to involve the husband because it is the decision of both the husband and the wife. If a woman accepts a method on her own, and if her husband or other family members, like her mother-in-law or sister-in-law, tell her that she will have to face many problems by using the method, she will not be able to continue its use and will drop the method. Subsequently, even if she doesn't wish to, she may become pregnant. So, by involving the husband, the use (continuation) of the method will improve. (Dr. N, age group 40-49)

Some health care providers indicated that they specifically requested the husband to attend the counselling session if the woman permitted. For example:

Yes. I call both; I call the husband specially.

(Dr. I, age group 30-39)

During counselling, we also involve the husband because both should know what is happening.

(Dr. G, age group 50+)

A few health care providers remarked that husbands were more likely to comprehend instructions than were women or that the husband's consent was required, and hence it was important that the husband also attended the counselling session. For example:

If the woman does not understand (the instructions), we tell her to call her husband and explain them to him; later, we do whatever they desire. (Dr. A, age group 50+)

The husband should be involved because the consent of both is required. (Dr. $\mathrm{H}$, age group 30-39) 
Health care providers were fairly unanimous in their perception that the final decision on which method to adopt was taken by the client, either on her own, or together with her husband.

\section{Health care provider perceptions about follow-up, discontinuation and switching}

Health care providers were mixed in their perceptions about the duration of use of injectable contraceptives, with a few noting that their clients tended to use the method for over a year and others noting that women rarely continued beyond two doses. There was more consistency across health care providers in terms of the factors underlying discontinuation, with almost all health care providers noting that the experience of side effects, specifically menstrual disturbances, was a leading reason for method discontinuation. For example:

Ninety percent of clients come on time and, on average, take four to five doses. (Dr. J, age group 50+)

Women are happy with this method and they come regularly for the next dose. (Dr. P, age group 50+)

Most clients take seven to eight doses and then discontinue. (Dr. K, age group 40-49)

In some exceptional cases, women may take injectables for four to five years, but mostly, women take four to eight doses only. (Dr. $\mathrm{N}$, age group 40-49)

Mostly, women are irregular. After taking the first, second or third dose, they won't come back for additional doses. (Dr. C, age group 50+) If menses stops, they think they have conceived and discontinue the method (Dr. A, age group 50+)
Mostly, women take one or two doses, then discontinue. They think that irregular menses will affect their health and so they discontinue the injection. (Dr. C, age group 50+)

Because people have this thing in their mind that menstrual blood is dirty blood and if it stays inside the body, it will harm the body. This is why most women discontinue using injectable contraceptives. (Dr. G, age group 50+)

They take around seven to eight doses, then they don't come; they drop the method because of side effects. (Dr. D, age group 30-39)

Half of all women discontinue it (injectable contraceptives) because of the problem of amenorrhoea. (Dr. G, age group 50+)

Women stop taking injectables because of the fear that if they don't get their periods, other problems will occur. They tell me that their family members say that it is necessary that menses should happen and bleeding should occur. (Dr. O, age group 40-49)

In a few cases, weight gain was also mentioned as a reason for discontinuation. Some health care providers said that women discontinued the method prematurely because they wished to become pregnant, associating the method with delayed return to fertility. For example:

After three to four doses, they stop coming because of the side effect of weight gain. (Dr. E, age group 30-39)

Women know that after stopping injectables, it will take one year to conceive. So, they stop after four to five doses. (Dr. H, age group 30-39)

Finally, some health care providers stated that the inconvenience of having to visit the facility every three months dissuaded women from continuing 
injectable contraceptive use. In contrast, the $\mathrm{Cu}-\mathrm{T}$ was seen as a more convenient one-time solution, and oral contraceptives were more easily accessible. For example:

One problem is coming every three months (for the injection). In some homes, there is not much care for women and there is no one to accompany them; so, they discontinue. (Dr. B, age group 40-49)

Health care providers were also asked about whether women who discontinued injectable contraceptive use adopted other methods, and the preferred method to which they advised women to switch. Three methods were typically suggestedtubal ligation, the IUCD and, to a lesser extent, oral contraceptives. Each method was perceived to have particular advantages: tubal ligation for those who had attained their family size, the IUCD for those who preferred a one-time method with no need for follow up, and oral contraceptives for women for whom regular menstruation was important. For example:

Women with two to three children get their sterilisation done. (Dr. K, age group 40-49)

After discontinuing injections, they prefer the IUCD and not (oral contraceptive) pills as they are afraid they will forget to take the pill regularly. (Dr. C, age group 50+)

Pills, so that menses is regular. (Dr. F, age group 40-49)

After (discontinuing) injectables, they prefer multiload (Cu-T). Women prefer the Cu-T because it can be removed at any time in case of any problem. (Dr. G, age group 50+)

Women who discontinue using injectables, get their tubectomy done if they don't want more children, (Dr. L, age group 50+)

\section{Health care provider perceptions about the inclusion of injectable contraceptives in the national programme}

Almost all health care providers who discussed their views about the inclusion of injectable contraceptives in the national programme were positive about the inclusion of the method. Several health care providers perceived that the inclusion of injectable contraceptives in the programme would enhance the basket of methods available to women and thereby offer them greater choice:

(Injectable contraceptives) should be included in the government sector programme, as one more method will be added for women. (Dr. B, age group 40-49)

Yes. It is a good method and should be included. By doing so, one more methods will be available for women; it will be easily available to them.

(Dr. H, age group 30-39)

Yes. It is a very good method. According to me, it should also be included in the government programme. If it is introduced in the government programme, it will be a fortunate thing for women because at this centre, I have seen that within two months of delivery, the woman conceives again. Even after delivering in a hospital, she doesn't use any contraceptive because no one informs her about anything (contraception). (Dr. J, age group 50+)

This method should be available in villages the way it is available in cities...there is a shortage of this method in rural areas; it should be available to women at their doorstep. (Dr. L, age group 50+)

Yes. It is a good method... if it becomes available, women will get one more choice, and a method with few side effects. (Dr. N, age group 40-49) 
Yes. It is a very good method. The failure rate is very low and there is no need for surgery.

Therefore, it is a better method than sterilisation.

(Dr. P, age group 50+)

Others argued that its inclusion in the programme would be advantageous, but must be accompanied by good counselling and follow-up. For example:

It is a good contraceptive method and should be included (in the government programme), but counselling and awareness about the method is required. (Dr. B, age group 40-49)

Yes. It is a good method and should be included (in the government programme), provided there is proper follow up, because there is no use in taking just one dose for three months.

(Dr. C, age group 50+)

Wherever these (contraception) facilities are provided, injectable contraceptives should be included. However, service providers should be fully trained and the other staff should also have information regarding injectables, how they act in the body and so on, because if counselling is good, the method will be accepted effectively. At many private places, clients are just given injectable contraceptives and don't receive full information regarding the method. Therefore, they come to us later with complaints-because they have half (inadequate) information and lack of awareness about the method, no knowledge of contraception.... If we provide correct and complete information to women who are less educated, its acceptance will increase. (Dr. K, age group 40-49)

Yes, provided that (it is introduced) after doing a complete study of the side effects of injectable contraceptives. It will be good if it is subsequently brought into the government programme. (Dr. I, age group 30-39)
The side effects of injectables remain for such a long time that we are not sure about the method... a lot of research is needed before including it in the government programme. (Dr. O, age group 40-49)

Several health care providers agreed that injectable contraceptives were an effective and safe method, but believed that their side effects deterred women from adopting the method. For example:

Injectables are a good method but they can be used only for a short period, for keeping a gap of a maximum of three years. But for longer durations, it is not so-for example, if a woman is 30 years old and she wants lifetime service, (contraceptive protection throughout her reproductive years), it will not be appropriate to give her injectable contraceptives for 15 years because other problems could arise. (Dr. K, age group 40-49)

Regarding injectable contraceptives, I would just like to say that it is a very good method but it is accompanied by the problem of secondary amenorrhoea. (Dr. J, age group 50+)

\section{Summary}

In-depth interviews with health care providers corroborated many of the issues raised by women who had used injectable contraceptives and those seeking to adopt a contraceptive method. Most health care providers noted that a number of their clients had adopted injectable contraceptives and that interest in the method was frequently expressed. However, they were mixed about their views on the appropriateness of injectable contraceptives as a viable method for their clientele. Almost all agreed that it is a safe and effective method, but expressed concerns about the side effects of the method. Several health care providers indicated 
that they would recommend the method to only certain categories of women, for example, those who do not want another child, or are older. Many noted that menstrual disturbances made injectable contraceptives an unattractive option for women, arguing that neither heavy bleeding nor amenorrhoea were acceptable side effects for women. A number of health care providers also mentioned that injectable contraceptives were not an appropriate non-terminal method for women intending to have another pregnancy on discontinuation of the method, that time to conception was far longer than that associated with the $\mathrm{Cu}-\mathrm{T}$ or oral contraceptives. It is notable that not a single health care provider specifically reported recommending injectable contraceptives to recently delivered or lactating women, although the method is recommended for such women.

Health care providers expressed different views about offering injectable contraceptives to poor or poorly educated women. Most health care providers maintained that the educational attainment status of their clients did not affect their decision to offer injectable contraceptives to them. Some, however, perceived that the poor and the poorly educated found it more difficult than others to comprehend how the method works, and still others feared that the poor would not be able to bear the cost of reinjections. This perception did not, however, deter most of these health care providers from offering the method to poorly educated and poor women; indeed, they reported that they spent more time explaining it to them than to others, and even recommended that the method be made more widely available to rural women through the programme.

For the most part, health care providers indicated that counselling entailed the provision of such information as the mechanics of the method (how often it must be taken) and the kind of side effects that may occur. All health care providers indicated that they informed women about such side effects as amenorrhoea and heavy bleeding, and that they should return to the clinic if they experienced these. Other side effects were mentioned less frequently (weight gain, for example). Several health care providers discussed the importance of including the husband in the counselling session, highlighting the link between the husband's involvement and the quality of subsequent method use, and the perception that many women would not adopt a method without having discussed it with their husband. All health care providers emphasised that the final decision on method use was made by the woman herself, alone or together with her husband.

Health care providers held different views about the average duration of injectable contraceptive use among their clients, some suggesting that women discontinued after the first or second injection and others suggesting that women used the method for considerably longer periods. In contrast, they were fairly unanimous about the key reasons for discontinuation. Leading reasons were the inconvenience of returning to the facility every three months for re-injections, cost, and side effects, notably menstrual disturbances. Health care providers noted, for example, that many women who experienced heavy bleeding or irregular periods discontinued using injectable contraceptives, fearing that they had a serious disease. Those who experienced amenorrhoea were reported to fear that they were pregnant, and discontinued the method as a result. Additionally, because of cultural practices that forbid menstruating women from entering the kitchen or praying, women who experienced heavy bleeding or irregular menstruation discontinued using injectable contraceptives because it affected their ability to perform these regular tasks. Several also noted that weight gain and the long waiting time to 
conception following discontinuation were additional reasons for discontinuing the method. Health care providers reported that method switching was evident among women who discontinued using injectable contraceptives for method-related reasons, and that the two methods to which women most commonly switched were tubal ligation and the IUCD.

Finally, health care providers were, for the most part, in favour of including injectable contraceptives in the national programme, in order that the basket of methods available to women would increase and provide women with greater choice. However, they argued strongly for certain prerequisites, such as comprehensive and sensitive counselling and effective follow up, for example. A few were sceptical; they believed that even with such improvements in the quality of services, few women in India would adopt or continue using injectable contraceptives because their side effects, notably menstrual disturbances, would discourage its use for both health and sociocultural reasons. 


\section{The way forward}

This chapter highlights the lessons learned for programming from the findings of our study, drawn from the experiences and perspectives of women who had used injectable contraceptives, women seeking contraception, and health care providers who offer injectable contraceptives to women. The findings of the study suggest a number of priority areas for action.

\section{Meet the demand for injectable contraceptives by including the method in the basket of contraceptives provided in public sector facilities}

Findings highlight that there is considerable interest in adopting injectable contraceptives and clearly a demand for a safe and effective non-terminal method that allows women to control their fertility confidentially, that does not require daily attention and that does not require to be inserted. Relatively low continuation rates are associated with injectable contraceptives globally and the finding should not be interpreted as a lack of demand. Indeed, the finding that more than one-fifth of all injectable contraceptive users continued the method for 12 months reiterates that there exists a demand for the method among certain groups of women. At the same time, evidence that many more discontinue injectable contraceptive use and immediately switch to a different method, thereby remaining protected against unintended pregnancy, suggests that injectable contraceptives play an important role in women's overall contraceptive strategies. Expanding the basket of contraceptives available to women will, therefore, enhance women's options and enable them to select the one whose features most suit their needs.

\section{Include a component of injectable contraceptives in the training offered to a range of health care providers}

Findings have suggested that health care providers who serve injectable contraceptive users may not be fully aware of the advantages and disadvantages of injectable contraceptives, the full range of side effects that are and are not associated with injectable contraceptives, and the counselling needs of potential users. It is important, therefore, to include a module on injectable contraceptives in the contraception-related training offered to a range of health care providers. For example, health care providers must be made aware of the appropriateness of injectable contraceptives for women who are recently delivered and lactating. Similarly, they should be trained to recognise that injectable contraceptives may satisfy the needs of women at different stages of the life cycle, for example, a newly delivered woman who wishes to space her next pregnancy, or a woman who is not medically eligible for an IUCD or does not want to have an IUCD inserted but is looking for a long-acting method. At the same time, they should be trained to appreciate that for some women, common side effects would likely be an intolerable disturbance in everyday life, and hence, should be equipped to counsel women so as to enable the woman to arrive at an informed decision about whether or not to adopt injectable contraceptives. 
Given that a number of women from our study were drawn from rural areas, it is important that training for frontline health workers, such as ANMs, ASHAs and AWWs, should also include information about injectable contraceptives, how they function and where they can be obtained, as well as basic information about potential side effects and how these should be managed.

\section{Expand awareness of injectable contraceptives at the community level}

Findings have confirmed that many women seeking to adopt contraceptives were unaware of injectable contraceptives, and at the same time, although the method is not available through the programme, a sizeable number of women do indeed opt for it. It is important, therefore, that efforts are made to inform communities, and women in particular, about injectable contraceptives, how they function, their cost, and where they can be obtained, as well as basic information about potential side effects.

\section{Improve the quality of care and counselling provided to injectable contraceptive users}

Findings suggest a disconnect between the views of health care providers on the comprehensiveness of counselling provided and women's views about the comprehensiveness of counselling received from health care providers with regard to injectable contraceptives. This disconnect highlights the need for health care providers to ensure that women are indeed making an informed choice, that they fully understand the implications of likely side effects for their life. Health care providers have acknowledged the importance of including husbands in the counselling session, and findings have confirmed that continuation beyond the first dose is indeed influenced by the role of the husband in decision- making. Provided that the woman agrees, it is important that counselling includes both the woman and her husband and that both are made fully cognisant of possible side effects.

As far as counselling is concerned, health care providers must be trained to ensure that counselling encompasses the full range of side effects associated with injectable contraceptives, as well as the action that the woman should take in case these side effects are experienced; the need to ensure that the woman has understood the implications of the method proposed, including injectable contraceptives, must be emphasised. For example, women, and their husbands if present, must be informed that amenorrhoea, irregular menstrual cycles and heavy bleeding occur to large numbers of injectable contraceptive users, that some women may gain weight, and that return to fertility may be slower than in the case of other contraceptives. Counselling sessions must also make women feel supported in case side effects are experienced, and emphasise the appropriateness of follow-up visits and phone calls in case the woman has concerns. Our finding that continuation rates were significantly higher among women who were provided comprehensive counselling underscores the critical role that health care providers play in ensuring method satisfaction.

\section{Make special efforts to inform injectable contraceptive users and potential users about health-related side effects}

Menstrual disturbances and weight gain are common and well-known side effects of injectable contraceptives, and return to fertility is typically longer among women who discontinue using injectable contraceptives than other methods. Women considering use of the method must be supported in making an informed decision, given these three key concerns. Irregular prolonged bleeding, 
amenorrhoea and/or heavy bleeding occur among most users of injectable contraceptives at some point while using the method, and women should be informed about this likelihood and the fact that side effects are typically not harmful. Although injectable contraceptives are a reversible method of fertility regulation, women also need to be informed that since the method is long-acting, it cannot easily be discontinued or removed from the body if a complication occurs or if pregnancy is desired. Counselling sessions should be supplemented by pamphlets and easy-to-read materials that highlight these side effects, emphasise that they are not harmful, and advise users about the action to take in case they are experienced.

\section{Reduce barriers to accessing supplies}

Findings have shown that 16 percent of all women who had discontinued using injectable contraceptives and between 12 percent and 28 percent of women who had discontinued using the method after various doses reported difficulty in accessing re-supplies. The leading access-related barrier was the inconvenience of accessing the facility every three months for re-injections. Long distances, limited freedom of movement and unavailability of an escort, and time spent in travelling to the facility for re-injections were significant deterrent to method continuation.
Efforts are needed that enable women to obtain reinjections closer to their homes and at reduced cost; the introduction of the method into the programme would go a long way in doing so.

\section{Conclusion}

In short, findings suggest that there is a demand for injectable contraceptives among women, and that both women and health care providers perceive a number of advantages associated with the method. As is well known, injectable contraceptives may not suit the lifestyle of many Indian women and our findings have confirmed that the method was adopted and was continued for one year or more, by relatively few women. Nevertheless, the fact that it was adopted by one in ten women seeking contraception, and was continued for one year or more by one in five women who adopted the method, reiterates that for a significant minority of women, its advantages exceed its disadvantages on balance. We conclude that there is indeed a demand for the method among this minority of women, and that the inclusion of injectable contraceptives in the basket of methods offered under the national programme, along with appropriate emphasis on health care provider training and on ensuring informed choice, will expand women's contraceptive choices and help in ensuring their reproductive rights. 


\section{References}

Ali, M. and J. Cleland. 2010. "Contraceptive switching after method-related discontinuation: Levels and differentials," Studies in Family Planning 41(2):129-133.

Caleb-Varkey L., J. W. Townsend., S. Vishwanath et al. 1998. Analysis of price change on the perceptions and use of DMPA among clients using reproductive health services in Uttar Pradesh, India. New Delhi: Population Council. Accessed on 18 February, 2011 at http://www.popcouncil.org/pdfs/frontiers/OR_TA/ Asia/ india_uttar.pdf.

Family Health International (FHI). 2010. Types, availability, and use of Injectables. FHI Briefs, India Brief 3. New Delhi: Family Health International.

Indian Council for Medical Research (ICMR). 1985. "Phase II randomized clinical trial with Norethisterone Oenanthate $50 \mathrm{mg}$ alone and in combination with $5 \mathrm{mg}$ or $2.5 \mathrm{mg}$ of either Etradiol Valerate or Cypionate as a monthly injectable," Contraception 32(4):383-394.

Indian Council for Medical Research (ICMR). 1990. "A multi-centric phase II comparative study of two hormonal contraceptive preparations NET-OEN (50mg) + E2 Valerate (5mg) given every month and NET-OEN (200mg) given every 2 months as intramuscular injection-A report of 12-month study," Contraception 42(2):179-190.

Indian Council for Medical Research (ICMR). 2008. Study on 2 Monthly Injectable Contraceptive Norethisterone Enanthate (200mg): Summary Report. Accessed on 18 February, 2011 at http://www.mohfw.nic.in/ dofw\%20 website/Final_Net-En_Report.pdf.

International Institute for Population Sciences (IIPS) and Macro International. 2007. National Family Health Survey (NFHS-3), 2005-06: India: Volume 1. Mumbai: IIPS.

International Institute for Population Sciences (IIPS) and Population Council. 2010. Youth in India: Situation and Needs 2006-2007. Mumbai: IIPS.

Lande R. and Richey C. 2006. Expanding services for injectables. Population Reports, Series K, No. 6. Baltimore: INFO project, John Hopkins Bloomberg School of Public Health.

Ministry of Health and Family Welfare (MOHFW) and United Nations Population Fund, India. 2005. Contraceptive updates: Reference manual for doctors. New Delhi: MOHFW, Government of India.

Office of the Registrar General \& Census Commissioner, India (ORGI). 2011a. Provisional Population Totals Paper 1 of 2011 India Series. New Delhi: Office of the Registrar General \& Census Commissioner, India.

Office of the Registrar General, India. (ORGI) 2011b. SRS Bulletin, volume 46 (1), December 2011. New Delhi: Office of the Registrar General, India.

Parivar Seva Sanstha (PSS). 2004. National workshop report on 'Expanding choices of contraception: injectables_learning from experience' held at Manesar in October 2004. New Delhi: Parivar Seva Sanstha. 
Population Council. 2003. Introducing DMPA Injectable Contraceptives to Private Medical Practitioners in Urban Gujarat. Frontiers in Reproductive Health. India: Population Council.

Sama. 2003. Unveiled realities: A study on women's experience with Depo-Provera, and injectable contraceptive. New Delhi: Sama- resource group for women and health.

Sarojini, N. B. and L. Murthy. 2005. "Why women's groups oppose injectable contraceptives," Indian Journal of Medical Ethics 2(1):8-9.

Rai, L., P. Prabakar and S. Nair. 2007. "Injectable depot medroxyprogesterone-a safe and an effective contraception for an Indian setting," Health and Population Perspectives and Issues 30(1):12-23.

Trussell, J. and K. Kost. 1987. "Contraceptive failure in the United States: A critical review of the literature," Studies in Family Planning 18(5):237-283.

Trussell, J. 2007. Contraceptive efficacy. In R.A. Hatcher., J. Trussell., A.L. Nelson., W, Cates., F.H. Stewart., D. Kowal. Contraceptive technology: Nineteenth revised edition. New York: Ardent Media.

United Nations Population Fund, India. 2004. Expanding contraceptive options: Experiences of users and providers with progestin only injectable contraceptive-DMPA, findings of a Multi-Centric Study. India: United Nations Population Fund.

United Nations. 2006. Levels and trends of contraceptive use as assessed in 2002. New York: United Nations Department of Economic and Social Affairs, Population Division.

Vaughan B., J. Trussell., K. Kost et al. 2008. "Discontinuation and resumption of contraceptive use: Results from the 2002 National Survey of Family Growth," Contraception 78(4):271-283.

World Health Organisation (WHO). 2010. Medical eligibility criteria for contraceptive use: A WHO family planning cornerstone. Geneva: WHO. 


\title{
Members of the study team
}

\author{
Investigators \\ Babita Bansod \\ Renu Devi \\ Geeta Gupta \\ Binit Jha \\ Najma Khan \\ Rita Kumari \\ Mithilesh Kumar \\ Shailendra Kumar \\ Brajesh Kumar
}

\section{Data Entry Operators}

Binit Jha

Shilpi Rampal

\section{Translation}

Monika Bindra

\section{Editor}

Jyoti Moodbidri

Komal Saxena

Administration

M.A. Jose 


\section{Authors}

Shireen J. Jejeebhoy, Senior Associate, Population Council, New Delhi

A.J. Francis Zavier, Programme Officer, Population Council, New Delhi 
(P Population Council

Zone 5-A, Ground Floor India Habitat Centre

Lodi Road

New Delhi 110 003, India 